\title{
Climate change in Central America and Mexico: regional climate model validation and climate change projections
}

\author{
Ambarish V. Karmalkar • Raymond S. Bradley • \\ Henry F. Diaz
}

Received: 6 January 2010/Accepted: 10 May 2011

(C) Springer-Verlag 2011

\begin{abstract}
Central America has high biodiversity, it harbors high-value ecosystems and it's important to provide regional climate change information to assist in adaptation and mitigation work in the region. Here we study climate change projections for Central America and Mexico using a regional climate model. The model evaluation shows its success in simulating spatial and temporal variability of temperature and precipitation and also in capturing regional climate features such as the bimodal annual cycle of precipitation and the Caribbean low-level jet. A variety of climate regimes within the model domain are also better identified in the regional model simulation due to improved resolution of topographic features. Although, the model suffers from large precipitation biases, it shows improvements over the coarse-resolution driving model in simulating precipitation amounts. The model shows a dry bias in the wet season and a wet bias in the dry season suggesting that it's unable to capture the full range of precipitation variability. Projected warming under the A2 scenario is higher in the wet season than that in the dry season with the Yucatan Peninsula experiencing highest warming. A large reduction in precipitation in the wet season is projected for the region, whereas parts of Central America that receive a considerable amount of moisture in
\end{abstract}

A. V. Karmalkar $(\square)$

School of Geography and the Environment, University of Oxford, South Parks Road, Oxford OX4 4YB, UK

e-mail: ambarish.karmalkar@ouce.ox.ac.uk

R. S. Bradley

Department of Geosciences, University of Massachusetts,

611 N. Pleasant St, Amherst, MA 01003, USA

H. F. Diaz

NOAA/ESRL/CIRES, 325 Broadway, Boulder, CO 80305, USA the form of orographic precipitation show significant decreases in precipitation in the dry season. Projected climatic changes can have detrimental impacts on biodiversity as they are spatially similar, but far greater in magnitude, than those observed during the El Niño events in recent decades that adversely affected species in the region.

keywords Regional climate change - Biodiversity . Central America

\section{Introduction}

The Mexican and Central American landmass has considerable topographic relief, which implies the existence of large gradients in many critical climate variables such as temperature, precipitation, humidity, and wind. The interactions between the complex topography of Central America (CAM) and the climate patterns determined by the neighboring oceans give rise to numerous climate and ecological zones, horizontally and vertically. These steep climatic gradients found on the mountain slopes have resulted in remarkable biodiversity in the region. The CAM region has been declared a biodiversity hotspot based on the existence of a large number of endemic species in the area and an exceptional loss of habitat in recent years (Myers et al. 2000). Spanning most of Central America, the biodiversity hotspot is home to lowland dry and montane/ cloud forests that host all subtropical and tropical ecosystems from central Mexico to the Panama Canal. Mountain ecosystems and species, where climate zonation is constrained by topography, are particularly susceptible to changing climate (Gasner et al. 2010; Parmesan 2006; Walther et al. 2002). Although ecosystems have adapted to 
changing conditions in the past, current environmental changes are occurring at a much faster rate, and pose a serious threat to biodiversity.

One of the most pressing issues in conservation biology is the observed global decline in amphibian populations (Stuart et al. 2004), which are particularly striking in Central and South America. One of the other important factors affecting biodiversity negatively is widespread deforestation that Central America has experienced in recent decades, especially in 1960s. The region originally had extensive forests, mainly species-rich rain forests but also rich dry forests; has only about one-third of them remain (Myers and Tucker 1987). In addition to these and other long-recognized threats-habitat loss from overexploitation, and exotic species introductions-amphibians in all biogeographic regions face several new threats, including climate change (Collins and Storfer 2003). The amphibian population declines in Costa Rica are thought to be driven by factors affected by climate (Pounds et al. 2006; Whitfield et al. 2007). Pounds et al. (1999) demonstrated that the dry-season mist frequency, an important factor responsible for supplying moisture to ecosystems in Costa Rica, is negatively correlated to SSTs in the equatorial Pacific and has decreased since the mid-1970s leading to dramatic decline in species populations and the extinction of the golden toad. A century-long record of hydroclimatology of Monteverde forest region reconstructed using high-resolution stable oxygen measurements from trees reveals that although there is no evidence of a warming trend, the extinction of the golden toad appears to have coincided with an exceptionally dry interval caused by the 1986-1987 El Niño event (Anchukaitis and Evans 2010). Pounds et al. (2006) argued that the extinction of the golden toad was due to the chytrid fungus that thrived as a result of changes in climate. The available data, however, simply do not support the hypothesis that climate change alone has driven the spread of pathogens, as Lips et al. (2008) show in the case of South America. Nonetheless, changes in the populations of birds and lizards occurred simultaneously and are all associated statistically with the same climatic patterns, implying a broad response to regional climate change (Pounds et al. 1999).

One of the conservation tactics for protecting biological diversity is the idea of biological corridors. The Mesoamerican Biological Corridor (Miller et al. 2001) stretches from Mexico through most of Central America providing an isolated habitat patch for the movement of species. It was started in 1998 to keep 106 critically endangered species from going extinct. But, the design and implementation of biological reserves and corridors critically depend on our understanding of the future climate change. Changes in the magnitude and the seasonal cycle of temperature, precipitation, humidity levels will affect ecosystem dynamics. In addition, changes in water availability or more importantly the shortage of water in the future could have negative impacts on hydropower generation and also on agricultural activities in the region. In many countries in Central America, hydropower is one of the important sources of energy. For example, hydropower contribution to the total energy production is significant in Costa Rica (90\%), Panama (60\%), and Guatemala (35\%). Therefore, a climate change study at spatial scales appropriate to address these problems is of paramount importance.

\subsection{IPCC projections for Central America}

Regional climate change projections for Central America and Mexico are summarized in the fourth assessment report (AR4) of the Intergovernmental Panel on Climate Change (Solomon et al. 2008, IPCC). Regional projections were obtained from the compilation of general circulation model (GCM) simulations (known as the multi-model data set; MMD) by dividing the world into a number regions as defined in Giorgi and Francisco (2000). One of these regions is Central America and Mexico spanning latitudes from $10^{\circ}$ to $30^{\circ} \mathrm{N}$ and longitudes from $83^{\circ}$ to $116^{\circ} \mathrm{W}$. The warming in Central America as simulated by the MMD under the SRES A1B scenario is greater than the global average warming in both boreal summer (JJA) and winter (DJF) seasons. The annual mean warming between 1980 to 1999 and 2080 to 2099 varies in the CAM region from $1.8^{\circ}$ to $5.0^{\circ} \mathrm{C}$ (Christensen et al. 2007), with half of the models within $2.6^{\circ}-3.6^{\circ} \mathrm{C}$ and a median of $3.2^{\circ} \mathrm{C}$. For Central America, 19 (out of 21) GCMs agree on the direction of change in precipitation, predicting a decrease in precipitation under the A1B scenario. The full range of IPCC projections for the area range from -48 to $9 \%$ change in mean precipitation with half the models between -16 to $-5 \%$ (Christensen et al. 2007). An increase in summer precipitation is projected in some parts of northeastern Mexico and the ITCZ region in the eastern Pacific. Giorgi (2006) developed a Regional Climate Change Index (RCCI) based on projected changes in the mean and variability of regional temperature and precipitation relative to their global values for 26 land regions of the world. This comparative index demonstrated that CAM is a climate change hot-spot, particularly due to a reduction in precipitation and increase in precipitation variability in the future scenarios. No other region in the tropics showed changes as large as Central America.

The horizontal resolution of the atmospheric components of the fully-coupled GCMs in the multi-model data set (MMD) ranges from 125 to $400 \mathrm{~km}$ with most models with resolutions over $250 \mathrm{~km}$. Studies focusing on CAM have either used station observations or GCM simulations 
(Rauscher et al. 2008; Small et al. 2007; Still et al. 1999), none of which have sufficient spatial resolution or station density to study regional/local-scale climate impacts in this topographically complex region. In fact, none of these models adequately resolve the narrow mountains of the Americas to be able to capture different climate regimes and climate variability in CAM. Rauscher et al. (2008) showed that only about half the models in the AR4 MMD simulated the spatial pattern and bimodal nature of precipitation of the MSD. One of the factors contributing to the bimodal nature of summer precipitation is locally intense convective activity (Magaña and Caetano 2005; Gamble and Curtis 2008) in the region, which coarse-resolution GCMs fail to capture. This highlights the pressing need to study climate change at a regional scale so that the regional implications of these changes on mountain biosphere reserves in Central America can be examined.

Simulations of global climates can be dynamically downscaled with the help of regional climate models (RCMs) to achieve high-resolution climate information. In the Americas, many regional climate modeling studies have focused on western North America (e.g. Mearns et al. 2009) and the Andes in South America (e.g. Urrutia and Vuille 2009; Seth et al. 2007). Regional climate models have been used to study the RCM's ability to reproduce modern-day climate of Central America (Hernandez et al. 2006) and to understand ocean-atmospheric dynamics of the tropical Americas (Tourigny and Jones 2009a, b). None of these studies, however, investigate regional climate change projections for the region. Here we study climate change in Mexico and Central America with the help of a dynamical downscaling technique using the UK Hadley Centre regional climate model (called PRECIS) described in the following section.

\section{Data and methods}

\subsection{Regional climate model: PRECIS}

The PRECIS (Providing REgional Climates for Impacts Studies) RCM is an atmosphere and land surface model of limited area and high resolution (Jones et al. 2004). It is derived from the third generation Hadley Centre Regional Climate Model (HadRM3), which is based on the atmospheric component (HadAM3) of the Hadley Centre coupled Atmosphere-Ocean GCM AOGCM), HadCM3 (Gordon et al. 2000). PRECIS can be applied over any area of the globe and was developed with the intention of supplying it to countries for vulnerability and adaptation studies. PRECIS can only be used in a set configuration as described in the model handbook (Jones et al. 2004) and the technical manual (Wilson et al. 2004). The lateral boundary conditions are provided by the Hadley Centre's global atmospheric-only model HadAM3P, which has horizontal resolution of $3.75^{\circ}$ longitude $(\sim 400 \mathrm{~km})$ and $2.5^{\circ}$ latitude $(\sim 300 \mathrm{~km})$. These data include surface pressure, zonal and meridional wind components, potential temperature, and water vapor. The lateral boundary conditions provide dynamical atmospheric information at the latitudinal and longitudinal edges of the model domain whereas the surface boundary conditions are only required over water, where the model needs time series of sea surface temperature.

PRECIS employs a regular latitude-longitude grid in the horizontal and hybrid vertical coordinates and also has a complete representation of the Coriolis force. The model has 19 vertical levels, the lowest at $\sim 50 \mathrm{~m}$ and the highest at $50 \mathrm{mb}$ with terrain-following $\sigma$ - coordinates $(\sigma=$ pressure/surface pressure) used for the bottom four levels, purely pressure coordinates for the top three levels and a combination in between. The land surface scheme employed is called MOSES (Met Office Surface Exchange Scheme) and is described in detail in Cox et al. (1999). The PRECIS RCM and the GCM employ identical representations of both the grid-scale dynamics and physics. The Hadley Centre uses a relaxation technique to drive the regional model where the values in the RCM are relaxed towards values interpolated in time from data saved every six hours from a GCM integration. Therefore, the regional model does not significantly deviate from the large-scale mean climate of the GCM, but produces high resolution climate information projections for a region consistent with the large-scale projections from the GCM.

\subsection{Experimental setup}

The model domain covers Central America, Mexico and a part of the surrounding oceans as shown in Fig. 1. The area between the outer and inner rectangles is a buffer zone of eight grid cells that is used to relax RCM values to the GCM integration and is omitted from the analysis. The effective grid size (excluding the buffer zone) is 120 $\times 163$. The area of interest, Central American landmass, is well away from the lateral buffer zone, which prevents noise from the boundary conditions contaminating the response. Two sets of experiments were performed at the horizontal resolution of $0.22^{\circ} \times 0.22^{\circ}(\sim 25 \mathrm{~km})$ : (1) Baseline run (1960-1990), which simulates modern-day climate against which any future climate change may be measured. (2) IPCC Scenario SRES A2 run (2070-2100) for climate change projections. The future level of global greenhouse gas emissions for this scenario are among the highest of the IPCC scenarios with atmospheric carbon dioxide concentration reaching $850 \mathrm{ppm}$ by 2100 (Nakicenovic et al. 2000). 


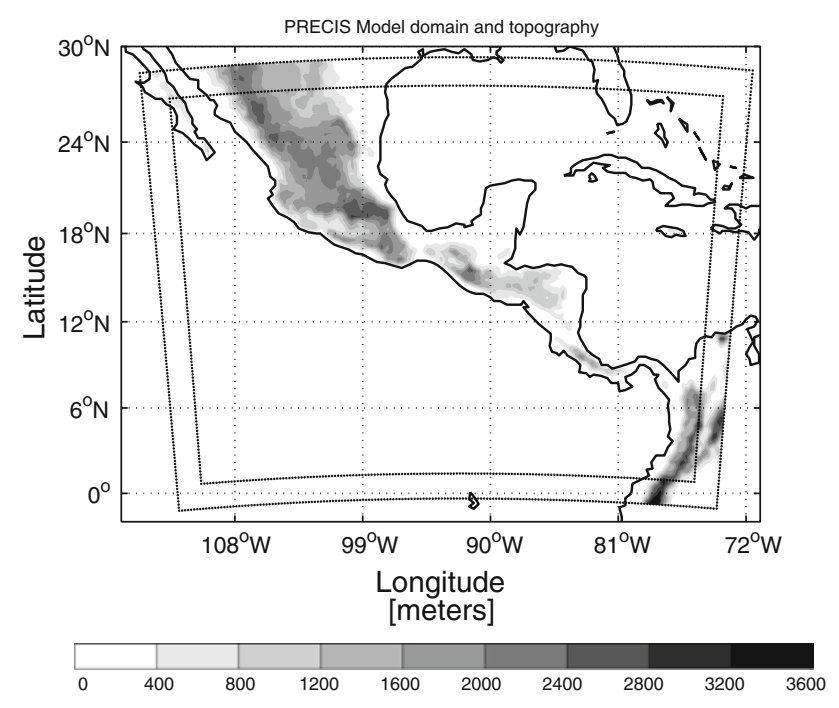

Fig. 1 PRECIS RCM model domain and the elevation map. The area between the outer rectangle and the inner rectangle is the buffer zone, where the boundary conditions data interacts with the RCM data. The model output for the area within the inner rectangle is included in the analysis

Boundary data are provided by one of three 30 year integrations of HadAM3P GCM. For the baseline run, PRECIS uses the observed SSTs (HadISST) data on a $1^{\circ}$ grid as surface boundary conditions and the observed evolution of greenhouse gas (GHG) concentrations is used to provide relevant information on the atmospheric component. For SRES A2 scenario runs (climates of 2070 to 2100), changes in SSTs and sea-ice derived from a coupled GCM (HadCM3) simulation are added to the observed value to give the lower boundary forcing for the atmospheric GCM and RCM simulations. The evolution of GHG concentrations is calculated off-line from the SRES emissions scenario data.

In the PRECIS RCM, the land surface model takes a complete seasonal cycle to come into equilibrium with the atmospheric forcing. Therefore, all the simulations are run for 31 years with a 30 year simulation available for analysis following a 1 year spin-up. Furthermore, three 30 year integrations of HadAM3P GCM are available to drive the RCM, but the results presented here are based on two members of the ensemble.

\subsection{Comparison data sets}

The model baseline (1961-1990) climate was validated against a number of data sets of temperature and precipitation available for the period. The comparison data sets included: (1) station data from the Global Historical Climatology Network (GHCN; Peterson and Vose 1997) (2) observed temperature and precipitation data gridded at $0.5^{\circ} \times 0.5^{\circ}$ resolution from the Climate Research Unit
(CRU; New et al. 1999; Mitchell and Jones 2005) (3) North American Regional Reanalysis (NARR) data at $0.29^{\circ} \times 0.22^{\circ}$ (lat-long) resolution, which is available from 1979 to present (Mesinger et al. 2006) (4) Observed precipitation data gridded at $0.5^{\circ} \times 0.5^{\circ}$ resolution from the Global Precipitation Climatology Centre (GPCC; Rudolf et al. 2005; Rudolf and Schneider 2005), and (5) CPC Merged Analysis of Precipitation data gridded at $1^{\circ} \times 1^{\circ}$ resolution (CMAP; Xie and Arkin 1997).

\section{Model validation}

The simulation of the modern-day climate must be validated against observations at a variety of temporal and spatial scales in order to gain confidence in the model's future projections. Most IPCC models (AR4 database of GCMs) have a cold bias of $0^{\circ}-3^{\circ} \mathrm{C}$ (Solomon et al. 2008) over Central America (CAM). For the CAM region, the multi-model scatter in precipitation in the IPCC models is substantial, but half of the models lie in the range of -15 to $25 \%$ of the observed annual mean. The largest biases occur during the boreal winter and spring seasons, when precipitation is low. Precipitation is underestimated in Central America in most GCMs due to insufficient spatial resolution (Rauscher et al. 2008) and underestimation of SSTs in the Gulf of Mexico and the Caribbean Sea (Dai 2006). The RCM was verified by testing its skill in simulating mean surface air temperature (at $1.5 \mathrm{~m}$; SAT) and precipitation (PRCP) and their variability at annual and interannual time-scales.

\subsection{Surface air temperature validation}

A comparison of the RCM mean annual surface air temperature with the CRU and NARR data sets is shown in Fig. 2. Clearly, the similarity between spatial patterns of SATs in the RCM (Fig. 2a,c) and the comparison data sets (Fig. 2b,d) confirms model's ability to simulate temperature in this topographically complex region. Note that the NARR data is available from 1979 to present and the comparison is limited to the last 11 years (1980-1990) of the baseline simulation (Fig. 2c,d). To quantify model biases, the RCM and NARR data are re-gridded to $0.5^{\circ} \times 0.5^{\circ}$ to match the CRU grid illustrated in Fig. 2b. Nonetheless, considerable differences in grid-point elevations between the re-gridded RCM and CRU/NARR data sets remain, which hinder the comparisons. Therefore, only grid points with elevation differences within $100 \mathrm{~m}$ (i.e., 772 out of 1,005 grid-points at CRU resolution) are considered in quantifying model biases. In general, the model shows a cold bias (mean bias $=-0.45^{\circ} \mathrm{C}$ ) when compared with the CRU data (Fig. 2e) and shows a smaller 

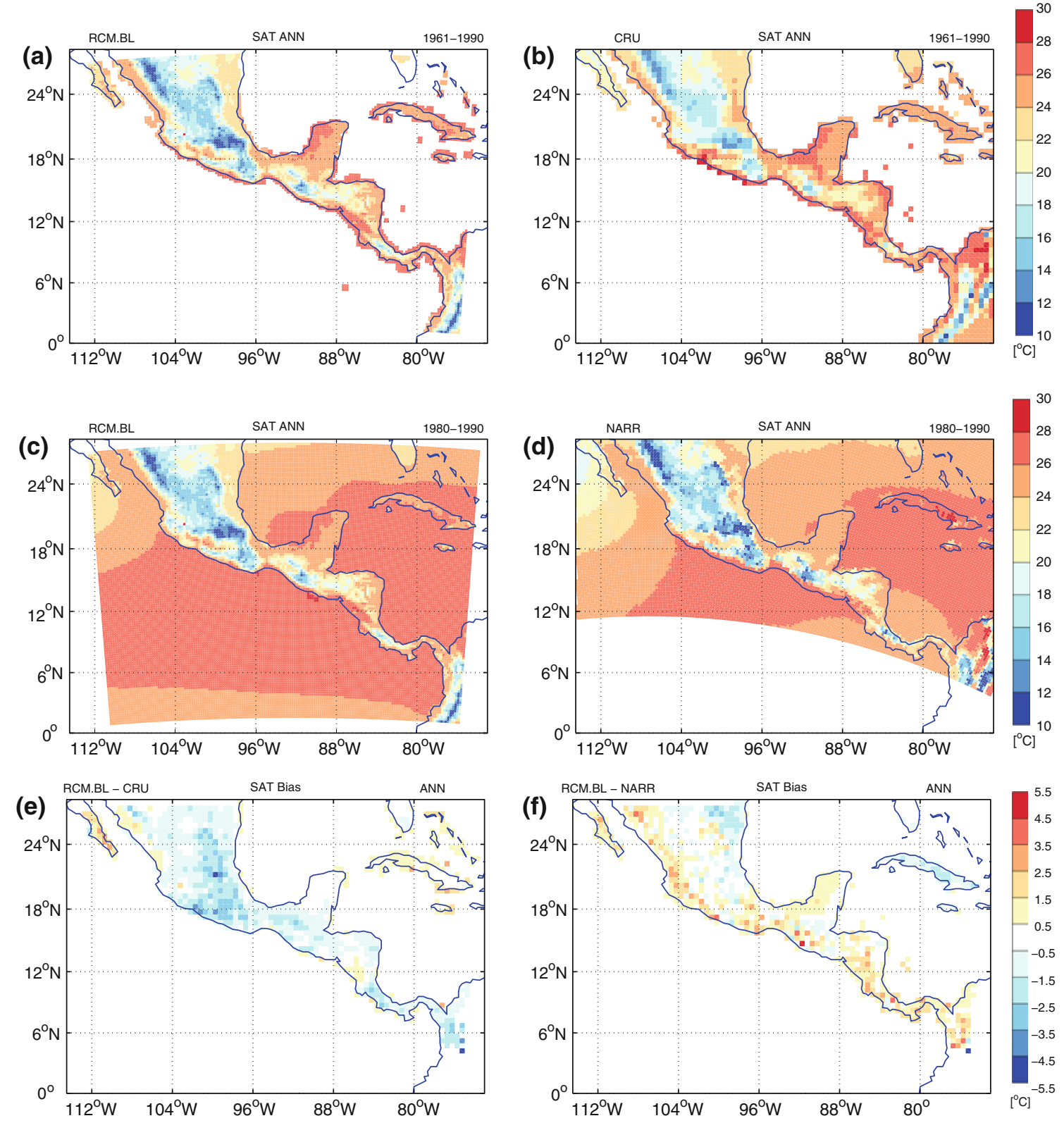

Fig. 2 Annual mean surface air temperature comparison between the a RCM baseline (RCM.BL) and b CRU data for the period 1961-1990 and between the $\mathbf{c}$ RCM.BL and d NARR data for the period 1980-1990. The RCM SAT bias is shown relative to e CRU and $\mathbf{f}$ NARR data

warm bias when compared to the NARR data (Fig. 2f). The differences between CRU and the RCM range from $3.1^{\circ}$ to $-4.3^{\circ} \mathrm{C}$ for individual grid-points. The cold SAT bias with respect to the CRU data may be partially due to lack of high-elevation station observations in the CRU analysis (Mitchell and Jones 2005) leading to underrepresentation of lower temperatures in the higher elevation regions, which results in a systematic overestimation of the air temperatures (Kim and Lee 2003).

The spatial pattern of the regional model SAT bias relative to the CRU data (RCM.BL-CRU) suggests that the bias may depend on grid-point elevation. The elevation dependency of the SAT bias is tested by dividing model grid-points into $100 \mathrm{~m}$ bins and by calculating model bias for each of these bins. Figure 3 demonstrates that the model SAT bias with respect to CRU increases with elevation. The model is colder than the CRU data by about $1^{\circ} \mathrm{C}$ for elevations greater than $500 \mathrm{~m}$ and the bias is as large as $-2^{\circ} \mathrm{C}$ for a number of grid-points with elevation over 2,000 m. A similar analysis of the model bias relative to the NARR SATs shows that the RCM is warmer than NARR at most elevations except for those over 2,500 m and that the model bias does not seem to depend on elevation. In fact, a perfect agreement between the RCM and 
NARR SATs (zero bias) is within one standard deviation of the bias at all elevations. This highlights the difficulty of evaluating model performance in mountainous regions such as Central America. Given the sparsity of high elevation observations that are available for use in the CRU data set, the significance of the model bias relative to CRU is difficult to assess. A direct comparison between the model SATs and the station data can tell us if the model bias is elevation dependent. The GHCN data has 168 stations in the CAM region with continuous SAT observations between 1961 and 1980, which are compared with the simulated SATs for that period. Stations with elevations greater than $1000 \mathrm{~m}$ are used to validate simulated lapse rate and elevation dependency of the model bias. To facilitate comparison between the station and gridded data, closest model and CRU/NARR grid-points to GHCN stations are found. Furthermore, those pairs of station and the gridded data that have elevation difference of more than $100 \mathrm{~m}$ are discarded from the lapse rate calculations. A similar analysis is also carried out for the WorldClim SAT data set (Hijmans et al. 2005), which is based on station data and is available as a mean of 1950-2000 SATs at 30 arc-seconds $(\sim 1 \mathrm{~km})$ resolution. Lapse rates for the all the data sets are tabulated in Table 1. The GHCN lapse rate is believed to be most accurate since it is based on direct

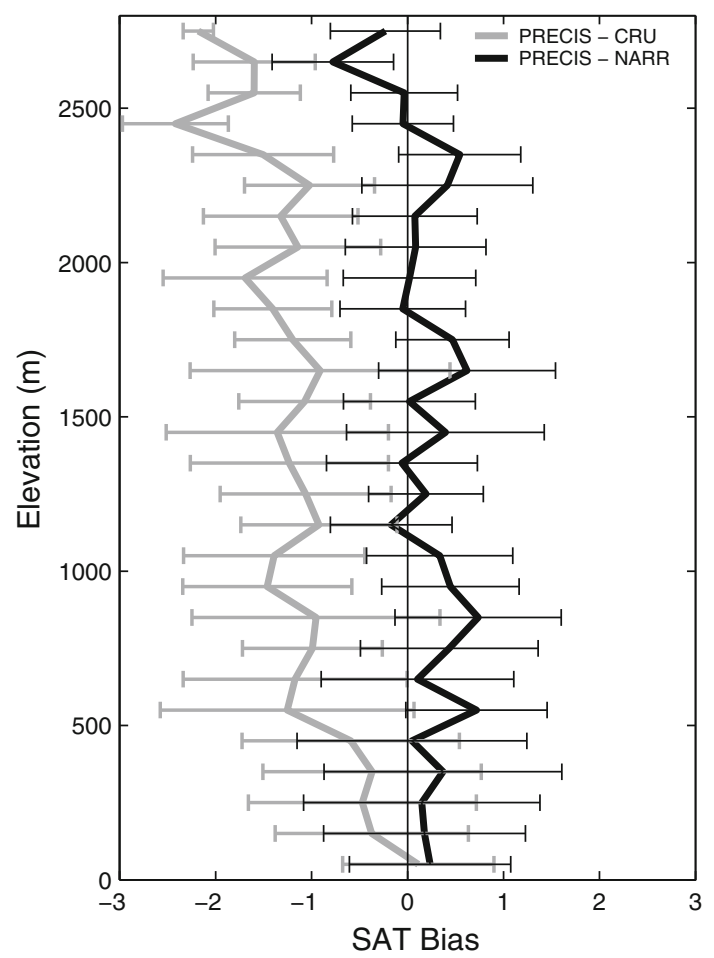

Fig. 3 The RCM SAT bias (RCM.BL-CRU and RCM.BL-NARR) in ${ }^{\circ} \mathrm{C}$ plotted as a function of elevation. The horizontal bars indicate one standard deviation around the mean SAT bias at every elevation bin
Table 1 Lapse rates for the RCM baseline simulation (RCM.BL) and the comparison data sets

\begin{tabular}{lll}
\hline Data set & Lapse rate $\left({ }^{\circ} \mathrm{C} / \mathrm{km}\right)$ & $r^{2}$ \\
\hline RCM.BL & -5.8 & 0.7 \\
GHCN & -5.2 & 0.7 \\
WorldClim & -5.1 & 0.85 \\
CRU & -4.7 & 0.85 \\
NARR & -5.0 & 0.8 \\
\hline
\end{tabular}

Lapse rates are calculated by carrying out linear regression on the elevation versus SAT data and $r^{2}$ denotes the Pearson's coefficient of significance

station observations. The lapse rate for the WorldClim data, based on a 50 year mean of station observations in the region, also matches very well with that calculated for GHCN. The GHCN lapse rate is steeper than that for the CRU data but not as steep as that determined from the model SAT. This suggests that at higher elevations CRU is warmer than the observed SATs and that the RCM indeed has a cold bias, though likely not as pronounced as suggested by the CRU-RCM comparison. An increased cold bias at higher elevations in PRECIS has also been detected in a modeling study over the Andes (Urrutia and Vuille 2009) and over the Hindukush-Himalayan region (Akhtar et al. 2008). Nevertheless, considering uncertainties in the comparison data sets, it can be concluded that the RCM biases compared to the CRU and NARR are modest.

\subsection{Precipitation validation}

The comparison data sets used for precipitation validation include gridded precipitation products from Global Precipitation Climatology Centre (GPCC; Rudolf et al. 2005; Rudolf and Schneider 2005) and the CPC Merged Analysis of Precipitation (CMAP; Xie and Arkin 1997). The GPCC database is an integration of several precipitation data sets including the CRU and GHCN data, which makes the GPCC data more reliable. The climate of Central America exhibits most of its variability in precipitation and the success of the model depends on how well it simulates large spatial PRCP variations and the seasonality of PRCP. The observed and simulated annual cycles of precipitation (area- and time-averaged) are shown in Fig. 4. The CAM region experiences two distinct seasons: a wet season from May through October and a dry season from November through April (Portig 1965). The region also presents a bimodal annual cycle of precipitation (Magaña et al. 1999) with the first PRCP peak in June, a decrease in July and August and the second peak in September or October as depicted (Fig. 4) by the GPCC and CMAP data. Figure 4 clearly shows that the GCM and the RCM have successfully captured the shape of the annual cycle of PRCP but 


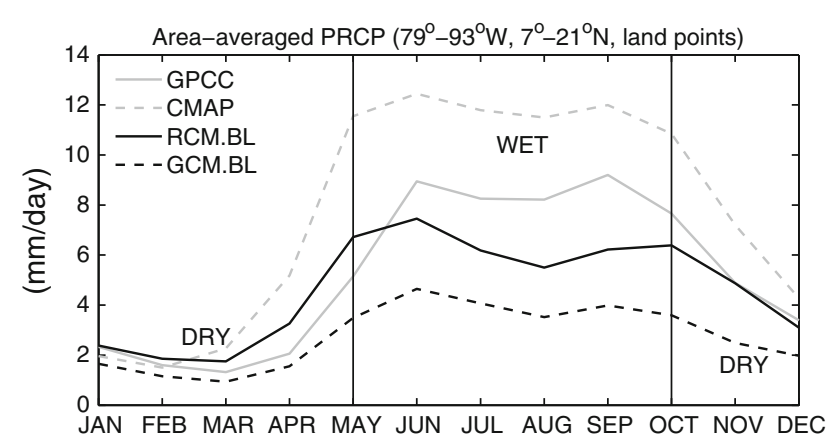

Fig. 4 Spatially and temporally averaged annual cycle of precipitation for the Central American landmass as described by GPCC, CMAP, RCM.BL, and GCM.BL data. CMAP data is averaged over the period 1979-1990 whereas all other data sets use a 30 year (1961-1990) average

not the magnitude. Compared to the CMAP and GPCC data, the GCM has underestimated precipitation in all months whereas the RCM is closer to the observed data, but is mostly drier in the wet-season months and wetter in the dry-season months. Due to strong seasonality of precipitation in the region, the mean climate setting and the model evaluation are discussed for wet and dry seasons separately.

\subsubsection{Wet season mean climate}

The Central American landmass is surrounded by the second-largest body of warm waters called the Western Hemisphere warm pool (WHWP) that covers the eastern tropical Pacific, the Gulf of Mexico, the Caribbean Sea, and the western tropical North Atlantic (Wang and Enfield 2001). The seasonal cycle of sea surface temperatures in this region affects the annual cycle of precipitation, convective activity and storm development (Wang and Fiedler 2006). In boreal summer, SSTs in the WHWP are greater than $28.5^{\circ} \mathrm{C}$ resulting in intense convection and precipitation (Wang and Lee 2007). Regions receiving copious amounts of precipitation in summer, within the model domain, are the ITCZ in the eastern Pacific and regions of the Intra-American Seas (IAS). The ITCZ related band of precipitation is clearly seen (Fig. 5a) in the Pacific, spanning latitudes between $6^{\circ}$ and $15^{\circ} \mathrm{N}$ in the CMAP data. Precipitation patterns over the Central American landmass are closely related to those over the surrounding oceans (Portig 1965) but are more complex as a result of topography (Fig. 5a,b). These spatial features of precipitation are well simulated by the GCM (Fig. 5c) as well as the RCM (Fig. 5d). The ITCZ is associated with an area of low mean sea level pressure (MSLP) controlled by solar heating, whereas the IAS region is dominated by the North Atlantic subtropical high (NASH) pressure system variability. The resultant surface winds in the IAS region are predominantly easterlies, whereas they are south-westerly in the Pacific, resulting in the convergence of surface winds over Central America (Fig. 5d) leading to wet conditions. In the IAS region, wind direction changes only slightly as the summer progresses. Winds in the Gulf of Mexico are mostly south-easterly or easterly and winds in the Caribbean are generally easterly, both responding to movement and intensity of the Atlantic subtropical high. Winds in the Caribbean Sea reaching the coast of Costa Rica and Panama remain north-easterlies through the year. Circulation over the Pacific and parts of Central America is controlled by the movement of the ITCZ through the seasonal cycle.

\subsubsection{Dry season mean climate}

Central America experiences a dry season from November to April (Portig 1965). The decrease in precipitation during this period (Fig. 5e,f) is a result of the ITCZ reaching its southernmost position, a decrease in SSTs in the eastern Pacific and the IAS to values lower than $28^{\circ} \mathrm{C}$ (Wang and Lee 2007), and an increase in trade winds strength. As a result, no major convective activity occurs in most of the WHWP region. Highest values of precipitation $(6-10 \mathrm{~mm} /$ day) in the eastern Pacific between $5^{\circ}$ and $10^{\circ} \mathrm{N}$ are a result of the convergence of low-level winds. In the Caribbean warm pool, organized convective activity is barely observed, due mainly to strong vertical shear. This spatial pattern of PRCP is well captured by the GCM (Fig. 5g) and the RCM (Fig. 5h). The trades reach their maximum speed in winter in the Caribbean Sea. Due to their uplift and condensation along the mountain slopes in Central America, wet conditions prevail on the Caribbean side in winter (Fig. 5h). The Pacific slopes, however, remain dry in winter due to the rain-shadow effect.

\subsubsection{Precipitation bias}

The precipitation bias is expressed here as percentage bias relative to the observed data. A large fraction of the RCM bias can be explained by simulation uncertainties in the GCM. Therefore, we discuss RCM as well as GCM precipitation biases here. The GCM underestimates precipitation in the Pacific compared to CMAP in the wet season (Fig. 6a). The RCM shows improvements in its PRCP simulation over the Pacific. In the Caribbean Sea and the Gulf of Mexico, the GCM and RCM biases relative to CMAP data have comparable magnitude in both seasons.

In general, the GCM precipitation bias relative to CMAP data is larger over land than that over the oceans in both seasons (Fig. 6a,e). The spatial pattern of GCM precipitation bias over land relative to GPCC is similar to that relative to the CMAP data in both wet and dry seasons (Fig. 6c,g). The RCM precipitation bias relative to the 

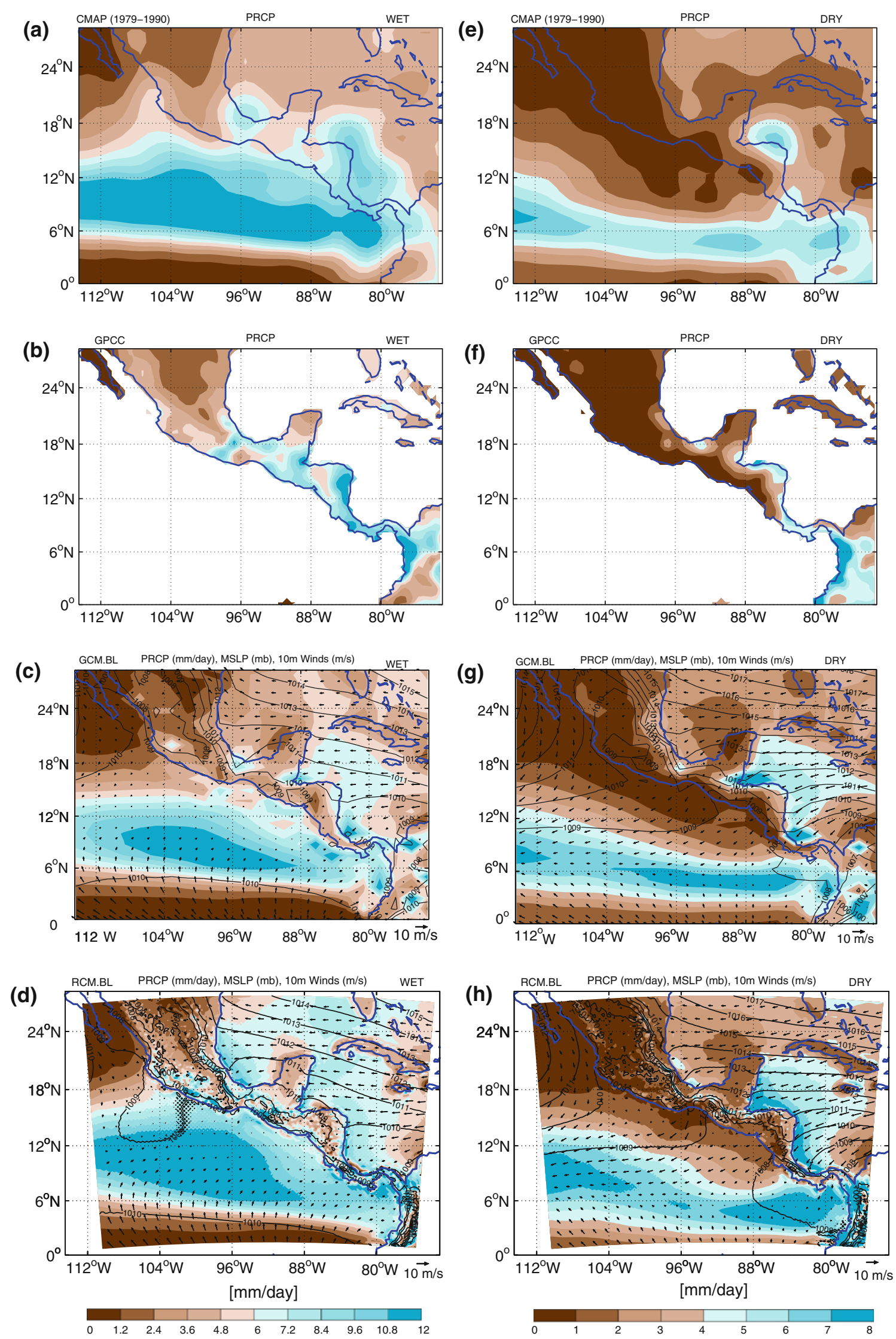
4 Fig. 5 Mean precipitation rate (mm/day) for the wet (a-d) and dry $(\mathbf{e}-\mathbf{h})$ seasons for CMAP (a, e), GPCC (b, f), GCM.BL (c, g) and RCM.BL (d, h). The simulated (GCM, RCM) sea-level pressure (contours) and $10 \mathrm{~m}$ winds (vectors) are overlaid on PRCP (colors). Note that all colors indicate positive values and color-scales are different for the wet and dry seasons

GPCC data shows, in general, a dry bias in the wet season and wet bias in the dry season. Additionally, the visual inspection of Fig. 6 suggests that the RCM overestimates precipitation in regions that are relatively dry (Mexico) and underestimates precipitation regions that are wet throughout the year (the Caribbean slopes of Central America). The GCM is very dry compared to GPCC and CMAP over Costa Rica where the RCM has small (positive as well as negative) PRCP biases. The mean seasonal GCM biases relative to GPCC for the model domain are $-30 \%$ and $21 \%$ for the wet and dry seasons respectively. The RCM bias relative to GPCC is smaller in the wet season $(0.9 \%)$ and larger in the dry season (63\%) compared to the GCM. It is important to note that a large percentage bias in the dry season in the RCM could result from a small absolute bias due to the meager amount of PRCP received in most of the region in this season.

Comparison between the RCM and the GCM and observed data shown in Fig. 5 suggests that the RCM exhibits greater skill than the coarse resolution model (GCM) at capturing fine scale spatial patterns of precipitation due to improved horizontal resolution and better representation of topography-induced variations. This structure is particularly evident from the mountains in Guatemala to Costa Rica. It is important to note that the annual cycle of PRCP varies greatly across the region and the one illustrated in Fig. 4 is not representative of the entire region. Model validation for temperature and precipitation indicates that the model performance may vary with season and spatially across the model domain. Therefore, a regionalization technique was employed to divide the model domain into a number of coherent regions that experience different climates, and model performance and climate change projections were quantified separately for each of these regions.

\subsection{Regionalization}

A combination of Empirical Orthogonal Functions (EOF) analysis and cluster analysis is used to divide the region into various climate zones that are similar in terms of their temperature and precipitation characteristics. An EOF analysis was first performed on simulated mean annual SAT and PRCP to identify variability modes captured by the model. The first six EOFs (the factor loadings) of temperature explain about $80 \%$ of the total variance whereas the first 9 EOFs of precipitation explain about $70 \%$ of the total variance in the data (the EOFs are not shown). These fifteen variability modes were used as an input to the $K$-means clustering algorithm (MacQueen 1967) to divide the model domain into climatologically similar regions. The division of the model domain into six regions reasonably describes the principal climate zones in Mexico and Central America (Fig. 7), although the choice of the number of clusters is arbitrary. The clusters distinguish between relatively cool and dry (regions 1,2) and warm and wet (regions 5, 6) areas of the model domain. The presence of the CAM Cordillera is responsible for varied climates on the windward and leeward slopes and those are distinguished as climatologically different regions (regions $1,3,5$ vs. 2, 4 and 6). Thus, the temperature and precipitation patterns modified by the topographic features determine six climate zones in Central America and Mexico. The performance of the GCM and the RCM seen in the spatial maps (Figs. 2, 4, and 6) is quantified using probability density functions (PDFs) for six regions shown in Fig. 7.

\subsubsection{Surface air temperature PDFs}

The modern-day distributions of mean monthly observed and simulated SATs for six regions are described using the Gaussian distribution (Fig. 8). Thirty-year monthly data for all the grid-points within every region are used to compute the regional PDFs for wet and dry seasons separately. Model biases, computed by comparing mean and standard deviation of the observed (CRU) and simulated (GCM.BL, RCM.BL) PDFs, are tabulated in Table 2. For both seasons, the modern-day mean monthly SATs increase and the distributions get narrower for regions from Mexico $(1,2)$ to southern Central America (regions 5, 6). Figure 8 shows that, in general, the mean SAT for the GCM.BL (thin gray) and the RCM.BL run (thin colored) are lower than the observed distribution (CRU; dashed gray) for all regions. The RCM SAT bias is smaller (by about a factor of 2) in the dry season compared to the wet season. The seasonal variability is also not fully captured by the RCM, and the distributions of the simulated SATs are narrower than the CRU SAT distributions. Note that region 5, which spans the Pacific slopes of Central America has low variability bias, whereas region 6 (the Atlantic side of the Cordillera) has the highest negative variability bias in both seasons.

Although, both the GCM and the RCM show modest SAT biases, it is not clear if the RCM improves SAT simulation in the region. The RCM SAT bias is smaller than that of the GCM in the dry season (except for region 1 ), whereas the case is exactly opposite in the wet season (except for region 6). Considering the coarse resolution of the GCM and uncertainties in the CRU data in 

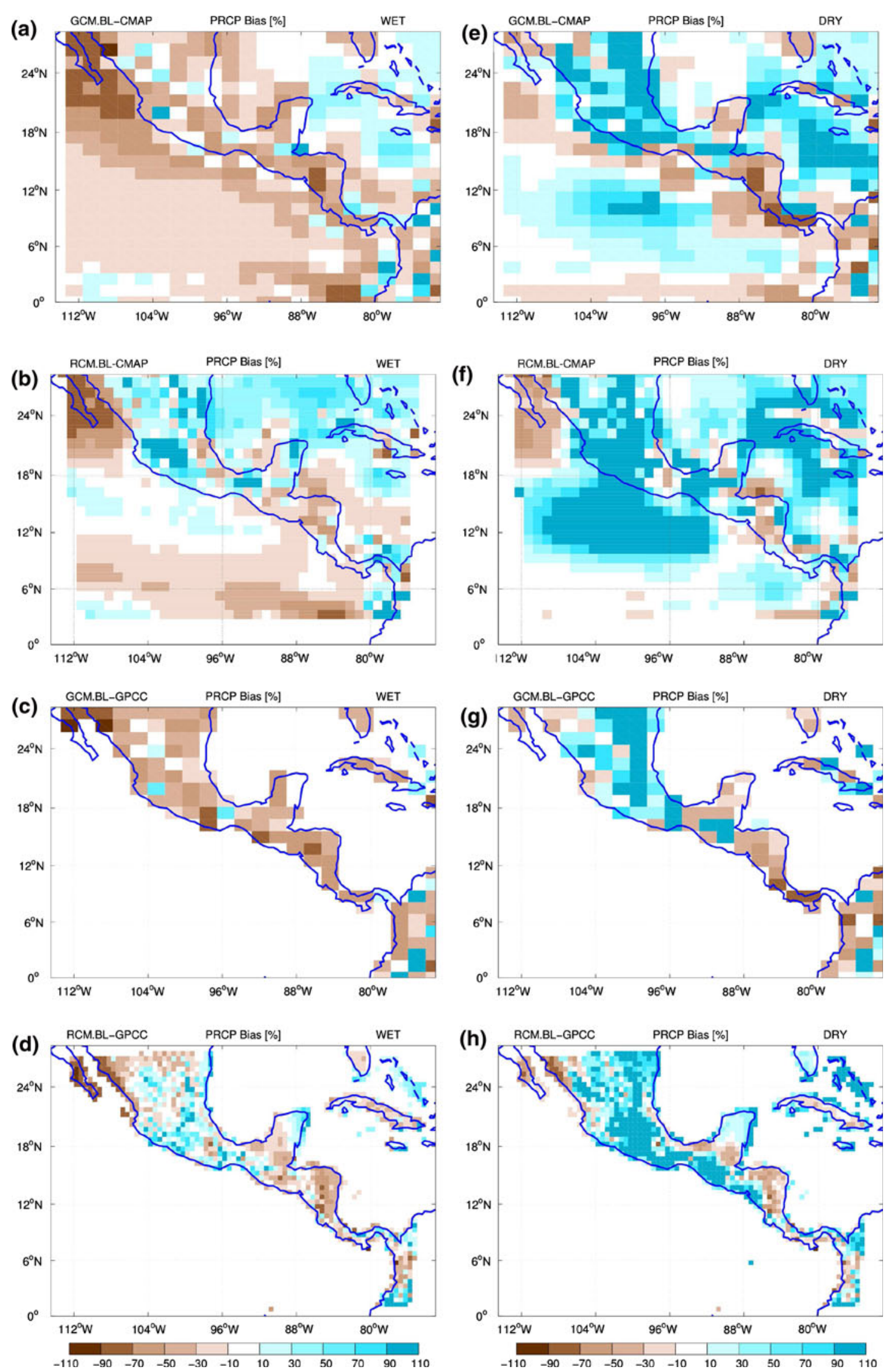
4 Fig. 6 Percentage precipitation bias for the wet (a-d) and dry (e-h) seasons for the GCM and the RCM relative to CMAP and GPCC. Note that the CMAP data from 1979 to 1990 is included in the analysis. All figure panels use same color-scale ranging from -110 to $110 \%$

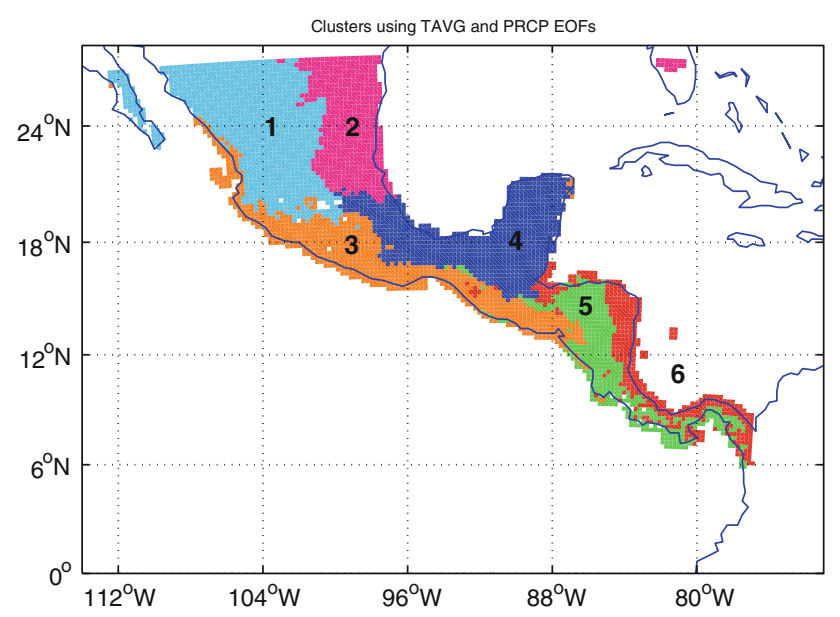

Fig. 7 Regional model domain divided into six regions using EOF and cluster analyses on simulated mean annual SAT and PRCP data

mountainous regions, the performance of the RCM relative to the GCM is difficult to assess. Nonetheless, the GCM as well as RCM show moderate biases in both seasons in Mexico and Central America.

\subsubsection{Precipitation PDFs}

The probability distribution functions of precipitation describing the distribution of monthly precipitation totals around the mean and their variability are calculated using the gamma distribution, which is computed using two parameters: shape $(\alpha)$ and scale $(\beta)$ parameter (Wilks 1995). Parameter estimation is given as $\mu=\alpha \beta$, $\sigma^{2}=\alpha \beta^{2}$, where $\mu$ denotes the mean and $\sigma$ the standard deviation of the distribution. The observed (GPCC) and the model (GCM.BL, RCM. BL) PDFs are compared in Fig. 9 and the precipitation biases are tabulated in Table 3 for all six regions. In the wet season, the GCM severely underestimates (by more than 30\%) PRCP in all six regions, which leads to underestimation of $\mathrm{PRCP}$ in the RCM as well (except for regions 2, 3). The RCM biases are, however, substantially smaller than the GCM biases suggesting that the high-resolution of the RCM improves PRCP simulation in this region. Precipitation variability biases described by the difference between the observed and simulated standard deviation are also smaller in the RCM compared to the GCM. In the dry season, Mexico and northern Central America (regions 1-4) show positively skewed PDFs and the GCM and RCM biases are positive and have comparable magnitudes. The RCM shows a notable improvement over the GCM in regions 5 and 6 (Pacific and Caribbean slopes of Nicaragua, Costa Rica, Panama), parts of which receive significant amount of moisture in the form of orographic PRCP in the dry season (Bruijnzeel and Proctor 1993). The GCM has insufficient resolution to resolve the Cordillera of regions 5 and 6 and therefore fails to capture topographic-induced PRCP. Although, the relative bias is very large in the dry season, the absolute bias is fairly small (shown later). In general, the mean and variability of simulated PRCP matches well with observations in regions that are relatively dry within the model domain (regions 1 and 2). Both the precipitation mean and variability are underestimated in the other four regions.

\subsubsection{Annual cycle}

The PDFs give information about the model's ability to simulate mean monthly SAT and PRCP and their variability, but not about its ability to capture the annual cycle of these variables. The annual cycles of simulated and observed SATs and PRCP are calculated and compared for all six regions. Central America shows very small seasonal variations in SAT (not shown), a characteristic of regions in the tropics, whereas Mexico (regions 1 and 2) show fairly large seasonal variations in temperature as a result of continentality and orography. The annual cycle of surface air temperature for all six regions shows close agreement with the CRU data but also shows cold bias in the model noted earlier. The SAT annual cycles are not shown here due to simplicity of their nature.

Annual cycles of precipitation are more complex and show well-defined wet and dry seasons and present a bimodal precipitation cycle (Fig. 10). The model domain (except for northwestern Mexico; region 1) experiences two precipitation maxima in a year. Northwestern Mexico (region 1) experiences North American Monsoon (Adams and Comrie 1997) showing a single precipitation peak around July. Overall, the GCM as well as the RCM are successful in capturing the shape of the PRCP annual cycle in all regions. The RCM is particularly successful in capturing the bimodal nature of the annual cycle and its variations in different parts of Central America. Precipitation cycles for regions on the Pacific and Atlantic slopes indeed show different bimodal features. Western Mexico (region 1) shows a single peak in precipitation in the summer and experiences very dry winters. The Pacific side of Central America (regions 3 and 5) has a bimodal PRCP cycle. Both June and September precipitation peaks are comparable for region 3 whereas the second peak is greater than the first PRCP peak in region 5. All regions on the 
Fig. 8 Probability distribution functions of monthly SAT in $\mathbf{a}$ wet and $\mathbf{b}$ dry seasons for the CRU data (dashed), and for the baseline (RCM.BL, GCM.BL; thin) and SRES A2 simulations (RCM.BL, GCM.BL; thick) for six regions defined in Fig. 7. Vertical lines mark means of respective distributions
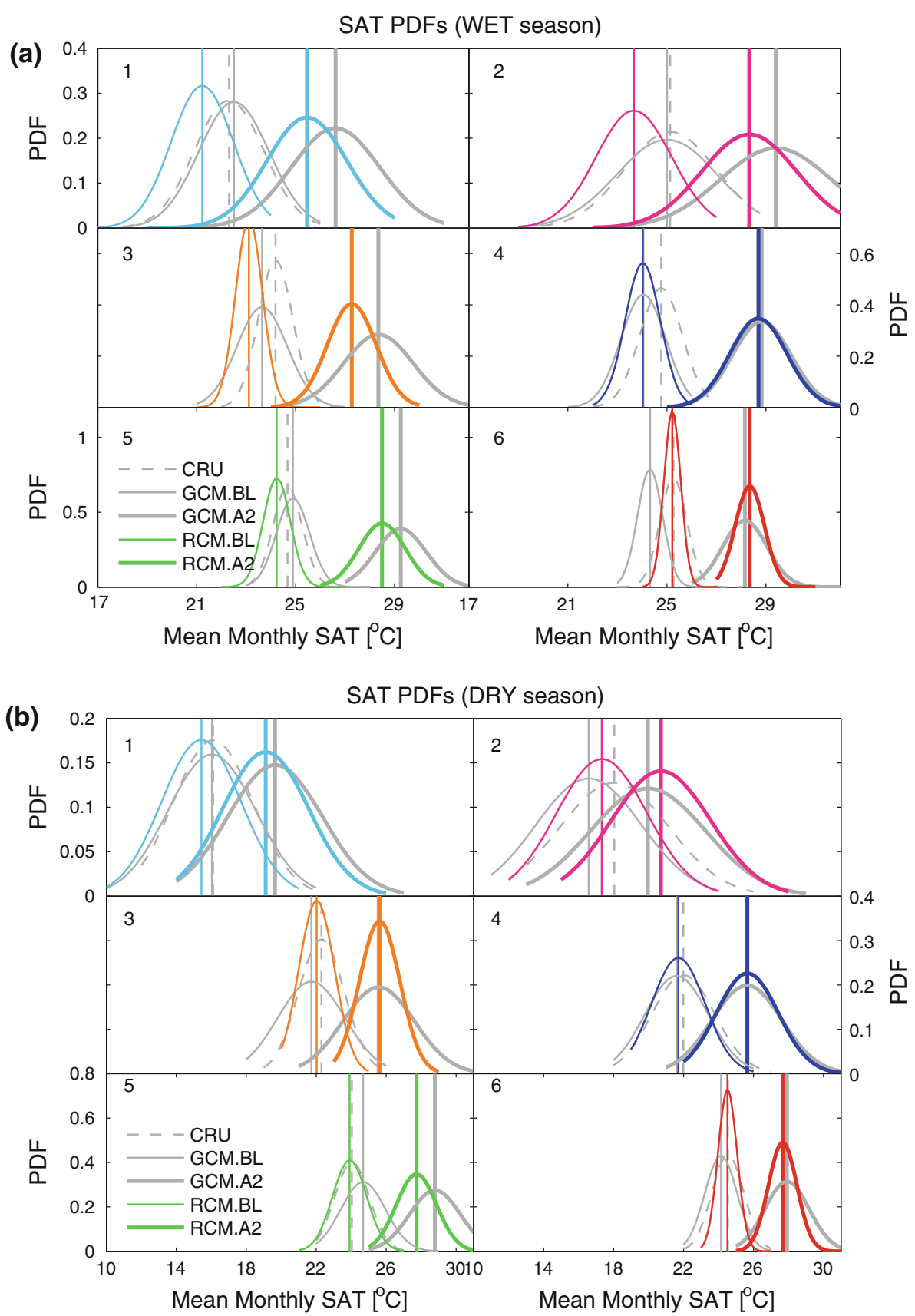

Atlantic side (regions 2, 4, 6) show a bimodal precipitation cycle. The eastern part of Mexico and the Yucatan Peninsula show a clear MSD feature where the months of July-August experience around $25-30 \%$ decrease in precipitation compared to June and September/October. The second peak in precipitation in the eastern Mexico occurs earlier than southeastern Central America. It is noteworthy, in general, the Atlantic side receives more PRCP in the dry (Nov-Apr) season than the Pacific side due to orographic cloud formation. As shown in the spatial maps of PRCP biases (Fig. 6), summer precipitation is underestimated in almost all regions (except for region 2) by the RCM, but by a smaller amount compared to the GCM. The RCM shows that the early wet season months (May, Jun) have smaller biases compared to those later in the wet season (Aug, Sep). This underestimation of precipitation in late summer could be related to the model's inability to simulate convective storms realistically. Biases in monthly PRCP for all six regions show that although the bias is reduced in RCM simulation, it follows the GCM bias very closely suggesting that the bias in the RCM is driven mostly by that in the GCM. 
Table 2 Model bias in the mean $(\mu)$ and variability $(\sigma$; standard deviation) of seasonal SAT relative to the CRU data for six regions defined in Fig. 7

\begin{tabular}{|c|c|c|c|c|c|c|c|c|}
\hline & \multicolumn{4}{|c|}{ Wet season } & \multicolumn{4}{|c|}{ Dry season } \\
\hline & \multicolumn{2}{|c|}{$\mu_{\text {bias }}\left({ }^{\circ} \mathrm{C}\right)$} & \multicolumn{2}{|c|}{$\sigma_{\text {bias }}(\%)$} & \multicolumn{2}{|c|}{$\mu_{\text {bias }}\left({ }^{\circ} \mathrm{C}\right)$} & \multicolumn{2}{|c|}{$\sigma_{\text {bias }}(\%)$} \\
\hline & GCM & RCM & GCM & $\mathrm{RCM}$ & GCM & $\mathrm{RCM}$ & GCM & RCM \\
\hline 1 & 0.2 & -1.1 & 1 & -10 & -0.1 & -0.7 & 10 & 0 \\
\hline 2 & -0.1 & -1.5 & 9 & -18 & -1.5 & -0.7 & -4 & -17 \\
\hline 3 & -0.5 & -1.1 & 47 & -22 & -0.6 & -0.3 & 46 & -22 \\
\hline 4 & -0.7 & -0.7 & 6 & -17 & -0.4 & -0.3 & 1 & -15 \\
\hline 5 & 0.2 & -0.4 & 13 & -8 & 0.6 & -0.1 & 29 & -2 \\
\hline 6 & -0.9 & 0 & -7 & -38 & -0.4 & 0 & 1 & -41 \\
\hline
\end{tabular}

\section{Key climatic features of the region}

\subsection{Caribbean low-level jet}

One of the interesting circulation features over the Caribbean Sea is the easterly zonal winds observed in the lower troposphere known as the Caribbean low-level jet (CLLJ). Previous studies have shown that the CLLJ has a maximum of easterly zonal wind near $925 \mathrm{mb}$ level (Amador 1998; Poveda and Mesa 1999; Amador 2008; Wang 2007) and it is a potential carrier of moisture to Central America, North America and also to the eastern Pacific (Duran-Quesada et al. 2010). Therefore, its influence on climate of the region needs to be investigated thoroughly. The Caribbean low-level jet is well simulated by the RCM in terms of its observed magnitude, position, and seasonal variations (i.e., the bimodal annual cycle) as described in previous studies (Wang 2007; Amador 2008). We examined the characteristics of the simulated CLLJ for Jan-Feb and Jun-Jul, periods when the CLLJ reaches its maximum values and also has different flow configurations. In winter, the CLLJ as simulated by the RCM is strong ( $\sim 15 \mathrm{~m} / \mathrm{s}$ at $925 \mathrm{mb})$, splits into two parts (Fig. 11a), and is vertically extended up to about $750 \mathrm{mb}$ (Fig. 11b). In summer, the RCM shows the jet speeds up to $12 \mathrm{~m} / \mathrm{s}$ at $925 \mathrm{mb}$ that pass over the Caribbean Sea towards the Gulf of Mexico (Fig. 11c) and that vertically extend up to about $700 \mathrm{mb}$ (Fig. 11d). These features match well with observations presented by Amador (2008) and Wang (2007).

\subsection{Orographic cloud formation}

Moisture carried by the CLLJ during the dry season is a crucial hydrological source to forests of Central America. Cloud forests in the region are immersed in persistent cloud cover at the vegetation level resulting from orographic uplift of the moisture-laden trade winds. This, so called, "horizontal precipitation" is greater than that from vertical rainfall events in some systems and accounts for a significant amount of the total precipitation in these regions in the dry season (Bruijnzeel and Proctor 1993; Clark et al. 1999) and changes in this amount in the future may significantly affect vegetation and species living on the mountains. The RCM provides information about convective precipitation in addition to the total precipitation amounts. Therefore, the fraction of non-convection precipitation (stratiform/frontal, orographic etc.) is determined by subtracting convective PRCP from the total PRCP amounts. The present-day non-convective PRCP fraction in Jan-Feb (Fig. 12a), when the CLLJ is at its maximum strength, seems to be of orographic origin since its spatial pattern shows high values along the windward and highelevation leeward slopes of Central America and Mexico. In the RCM, the windward slopes of the American Cordillera from south-eastern Mexico to Panama receive over $70 \%$ non-convective PRCP in Jan-Feb. The 30 year mean fractional cloud cover as simulated by the RCM and GCM for Jan-Feb is shown in Fig. 12b and c, respectively. Highresolution of the RCM results in heterogeneous spatial pattern of cloud cover over land compared to that from the GCM. For example, the region of Costa Rica shows higher fractional cloud cover in the RCM compared to the GCM. As a result, the dry season precipitation bias is reduced in the RCM in these regions (regions 5 and 6; see Table 3). Underestimation of precipitation along the leeward slopes (region 5) and overestimation along the windward slopes (region 6) is also detected in a PRECIS study over South America (Urrutia and Vuille 2009; Buytaert et al. 2010) and other RCM studies as well (Caldwell et al. 2009; da Rocha et al. 2009).

\subsection{El Niño Southern Oscillation (ENSO) and Central America}

The dominant factor affecting the interannual variations of the Central American climate is variability in the surrounding oceans. In particular, climate variability in the eastern and central Pacific has a near-simultaneous effect on Central American temperature and precipitation (Enfield and Mayer 1997; Enfield and Elfaro 1999). El Niño Southern Oscillation (ENSO), which is the dominant mode of SST and atmospheric variability in the Pacific, is the main forcing mechanism of climate variability in Central America (Giannini et al. 2000, 2001; Waylen et al. 1996). An EOF analysis of the mean annual SATs over land in Central America produces variability modes that do show the influence of the neighboring oceans. The first, third and fourth SAT modes are associated with the sea surface temperature variability in the Pacific, the Gulf of Mexico and the Caribbean Sea respectively. The first mode explains $36 \%$ of the total interannual variability of the land 
Fig. 9 Probability distribution functions of monthly PRCP in $\mathbf{a}$ wet and $\mathbf{b}$ dry seasons for the GPCC data (dashed), and for the baseline (RCM.BL, GCM.BL; thin) and SRES A2 simulations (RCM.BL, GCM.BL; thick) for six regions defined in Fig. 7. Vertical lines mark means of respective distributions
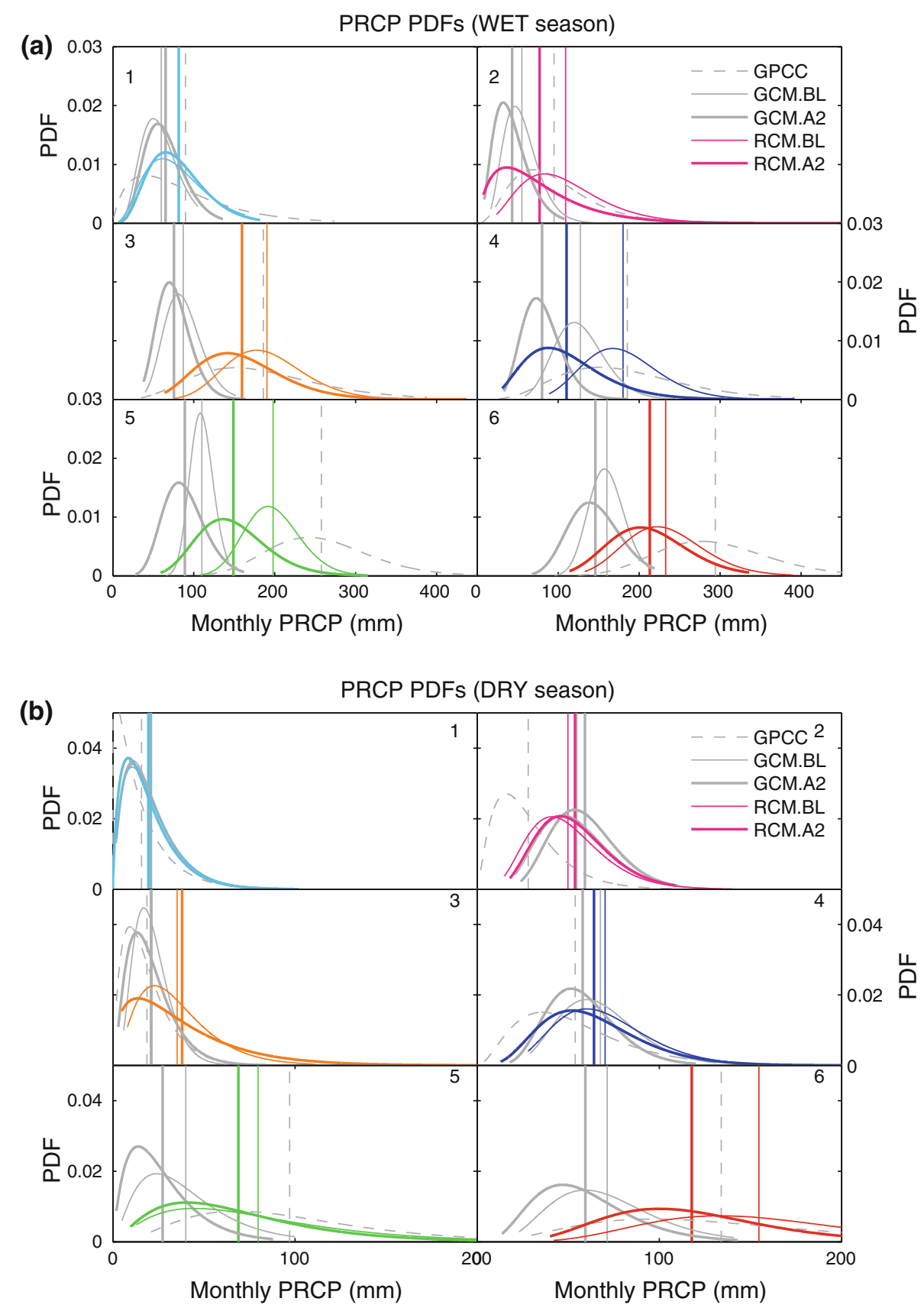

SATs in the region (Fig. 13a). Its corresponding principal component (Fig. 13b) time series correlates strongly $(r=$ 0.8 ; significant at the $95 \%$ level) with the ENSO index (3.4 region) time series. The spatial pattern of the first mode has high loadings all across Central America (Fig. 13a) illustrating the strong effect of the ENSO variability on Central American SATs. The maximum impact of the Pacific SST variability is felt on the Pacific slopes of the Cordillera as represented by the highest loading values in that region. This was one of the modes used as an input to the cluster analysis. We note that since the baseline experiment uses observed SST as a surface boundary condition, its effect on the land SATs is realistically simulated by the model for the present-day simulation.

\section{Temperature response to climate change}

\subsection{Surface air temperature response}

The Central American surface air temperature follows incoming short-wave radiation and shows homogeneous variations in the annual cycle. The annual range of SATs, however, is small and is far exceeded by the diurnal cycle 
Table 3 Model bias in the mean $(\mu)$ and variability ( $\sigma$; standard deviation) of seasonal PRCP relative to the GPCC data for six regions defined in Fig. 7

\begin{tabular}{|c|c|c|c|c|c|c|c|c|}
\hline & \multicolumn{4}{|c|}{ Wet season } & \multicolumn{4}{|c|}{ Dry season } \\
\hline & \multicolumn{2}{|c|}{$\mu_{\text {bias }}(\%)$} & \multicolumn{2}{|c|}{$\sigma_{\text {bias }}(\%)$} & \multicolumn{2}{|c|}{$\mu_{\text {bias }}(\%)$} & \multicolumn{2}{|c|}{$\sigma_{\text {bias }}(\%)$} \\
\hline & GCM & $\mathrm{RCM}$ & GCM & $\mathrm{RCM}$ & GCM & $\mathrm{RCM}$ & GCM & $\mathrm{RCM}$ \\
\hline 1 & -33 & -9 & -64 & -39 & 30 & 35 & -9 & -2 \\
\hline 2 & -42 & 15 & -57 & 6 & 95 & 78 & 10 & 15 \\
\hline 3 & -53 & 2 & -72 & -39 & 15 & 87 & -26 & 59 \\
\hline 4 & -31 & -3 & -61 & -40 & 25.5 & 30 & -28 & -15 \\
\hline 5 & -57 & -23 & -77 & -45 & -59 & -18 & -53 & -1 \\
\hline 6 & -45.5 & -21 & -68 & -30 & -47 & 15 & -58 & -19 \\
\hline
\end{tabular}

(Hasternath 1991). At a regional scale, the annual cycle of SAT as well as its interannual variability is greatly influenced by the surrounding oceans. On both the interannual and decadal timescales, the eastern Pacific and the Atlantic SST variability has a clear influence on the SATs in Central America (Alfaro 2002), which occurs via interactions with the overlying troposphere (Mestas-Nuñez and Enfield 2001). In particular, Central America has a strong climate association with the ENSO region of the eastern equatorial Pacific (Enfield 1996; Giannini et al. 2001), in which warm (cold) SST events are correlated with warm (cold) SAT anomalies. Therefore, the study of future change in the surface air temperature should entail, along with looking at the mean change, an examination of changes in the annual cycle of warming and in the interannual variability.

First, the change in SATs between the SRES A2 and the baseline experiment ( 30 year means) is presented here. The
RCM simulation for the SRES A2 scenario shows significant warming over Mexico and Central America. Mean seasonal warming over land is higher in the wet season $\left(4.1^{\circ} \mathrm{C}\right)$ than that in the dry season $\left(3.5^{\circ} \mathrm{C}\right)$. Warming over land in Mexico and Central America (Fig. 14) ranges from $1.4^{\circ}$ to $6.5^{\circ} \mathrm{C}$ in the wet season and from $1.7^{\circ}$ to $5.2^{\circ} \mathrm{C}$ in the dry season for individual grid-points. The higher wet season warming is likely associated with a large projected decrease in precipitation (discussed later), which results in a decrease in cloud cover and an increase in the sensible heat flux from the surface. Although, warming is higher in the summer months, there is no significant change in the shape of the SAT annual cycle under the SRES A2 scenario (not shown).

The change in the surface air temperature mean and its variability is quantified using the probability density functions. The present day (BL) and future (A2) SAT distributions for the GCM and the RCM for six regions are shown in Figure 8 and the projected changes in the mean and the width $(2 \sigma)$ of the distributions for the RCM are tabulated in Table 4. Largest increase in SAT within the model domain is seen for the Yucatan Peninsula (region 4) where warming is $4.7^{\circ} \mathrm{C}$ for the wet season and $3.9^{\circ} \mathrm{C}$ for the dry season. The Caribbean coast of Costa Rica and Panama (region 6) shows lowest warming within the model domain in both seasons. An increase in the width of the distribution during the wet season is projected to be high (60-80\% increase) in Central America (regions from 3 to 6). The dry season will experience a modest increase in the width of all six distributions, increasing equatorward. A large increase in SAT variability in regions along the Pacific side of Costa Rica could be associated with the
Fig. 10 Simulated and observed annual cycles of precipitation for six regions shown in Fig. 7. Results from the RCM baseline (RCM.BL; thin colored) and GCM baseline (GCM.BL; thin gray) simulations are compared with the GPCC data (dashed). The figure also shows PRCP annual cycles under the A2 scenario for the RCM (RCM.A2; thick colored) and the GCM (GCM.A2; thick gray)

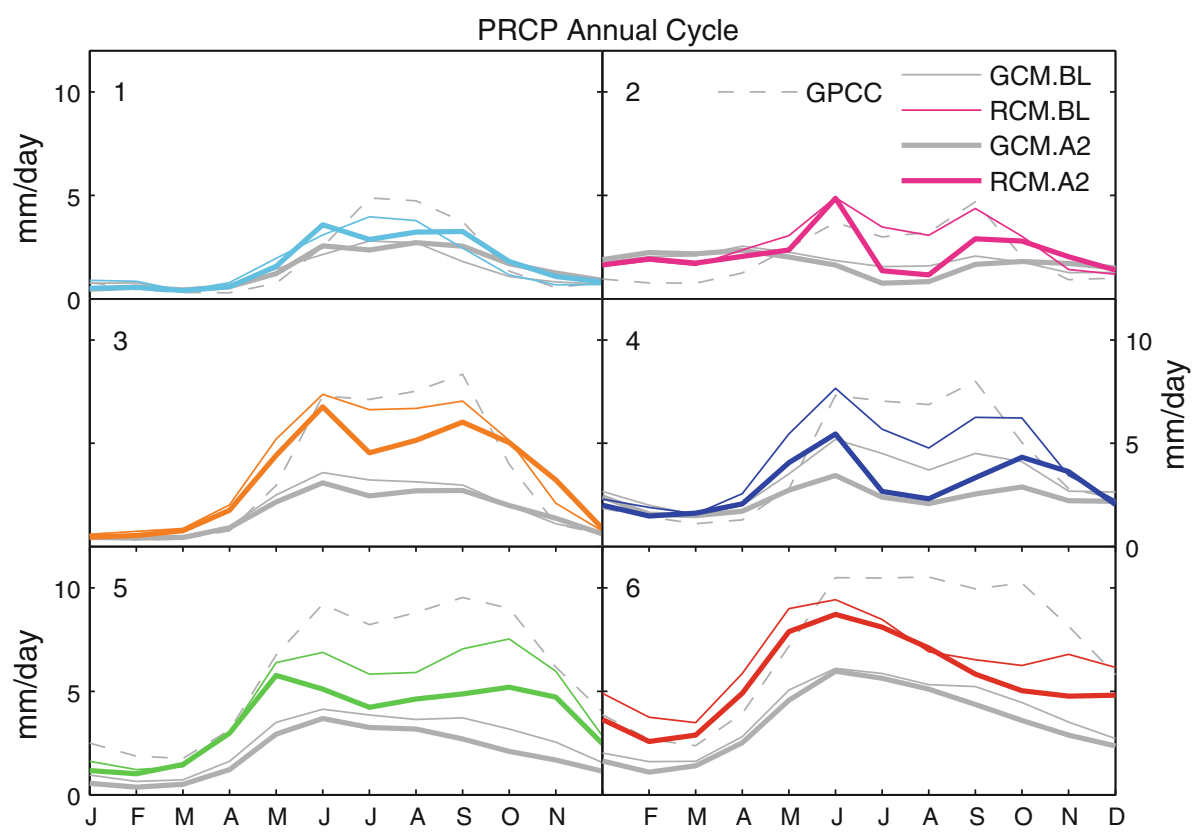



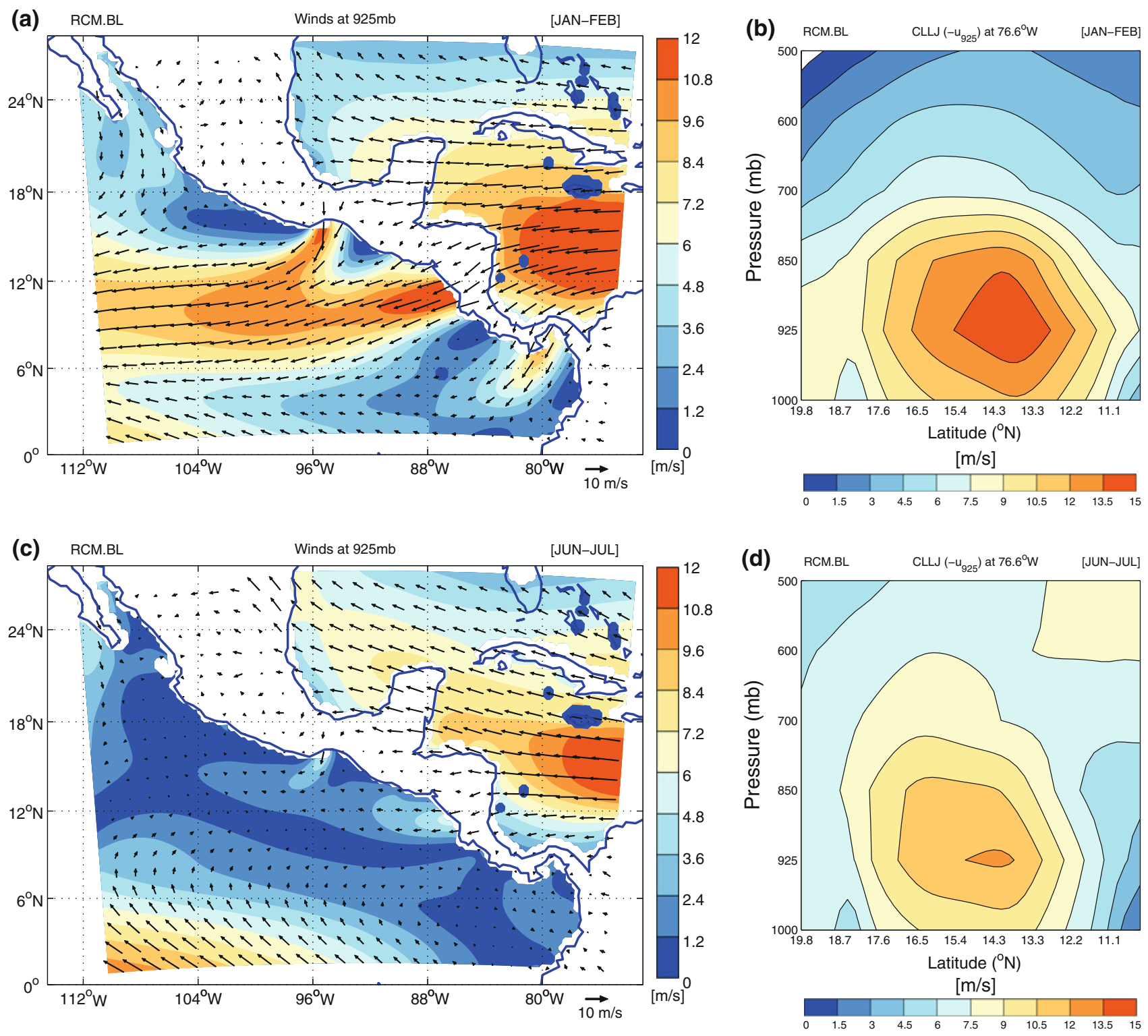

Fig. 11 Horizontal and vertical structure of the CLLJ i.e. zonal $925 \mathrm{mb}$ winds for the RCM.BL run for the months of (a, b) Jan-Feb and (c, d) Jun-Jul. Note that the plotted values are for $-\mathrm{u}$

large SST increase in the eastern equatorial Pacific. It is important to note that the future SAT distributions lie almost completely outside the present-day distributions for regions (3-6) in Central America. This shows that the projected lowest SATs in the future are lower than presentday highest temperatures in these regions.

\subsection{Free air temperature response}

Future warming is expected to be amplified with elevation in the lower troposphere, which has significant implications for the mountainous regions of the world (Bradley et al. 2004, 2006). In fact, mountain regions throughout the world have experienced large upward shifts in freezing levels in recent decades (Diaz et al. 2003; Vuille and Bradley 2000). Climate models consistently show tropospheric amplification of surface warming in response to well-mixed greenhouse gases (Santer et al. 1996; Hansen et al. 2002; Tett et al. 2002). Maximum warming in these models occurs in the middle and upper troposphere. Observations of tropospheric temperatures corroborate these results. Santer et al. $(2005,2008)$ have demonstrated that the tropospheric temperature change can be seen in satellite- and radiosonde-based measurements. The increase in water vapor and the associated increase in latent heat release during condensation seems to be a cause of this warming aloft. The projected change in tropospheric mean annual temperature as simulated by the RCM for a transect along the Central American Cordillera is 


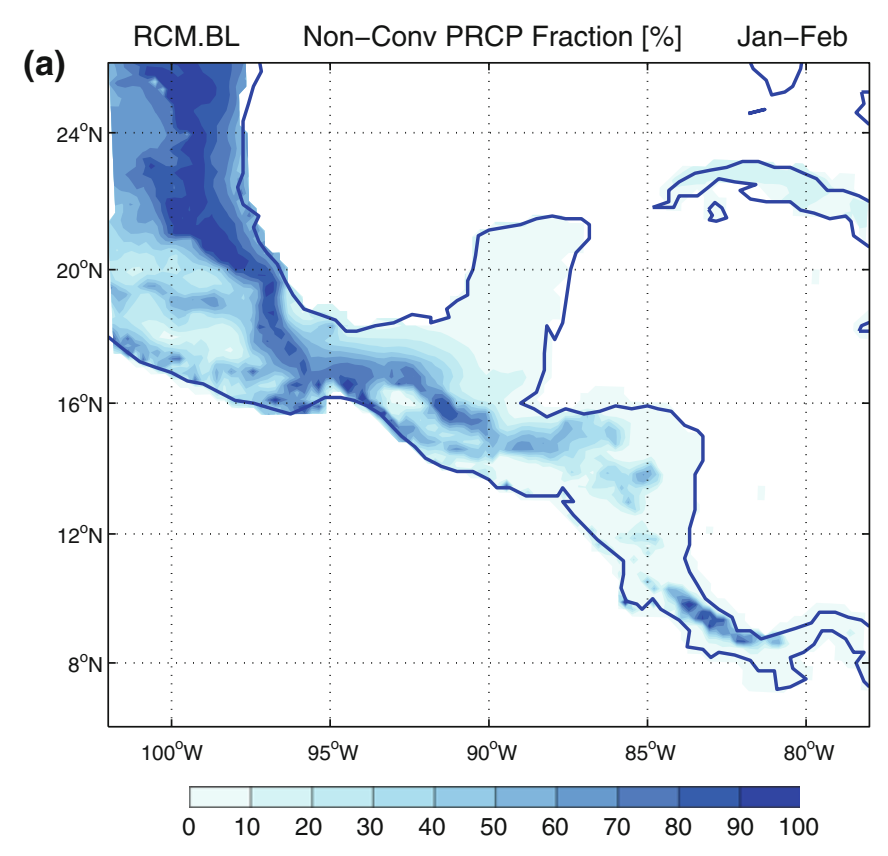

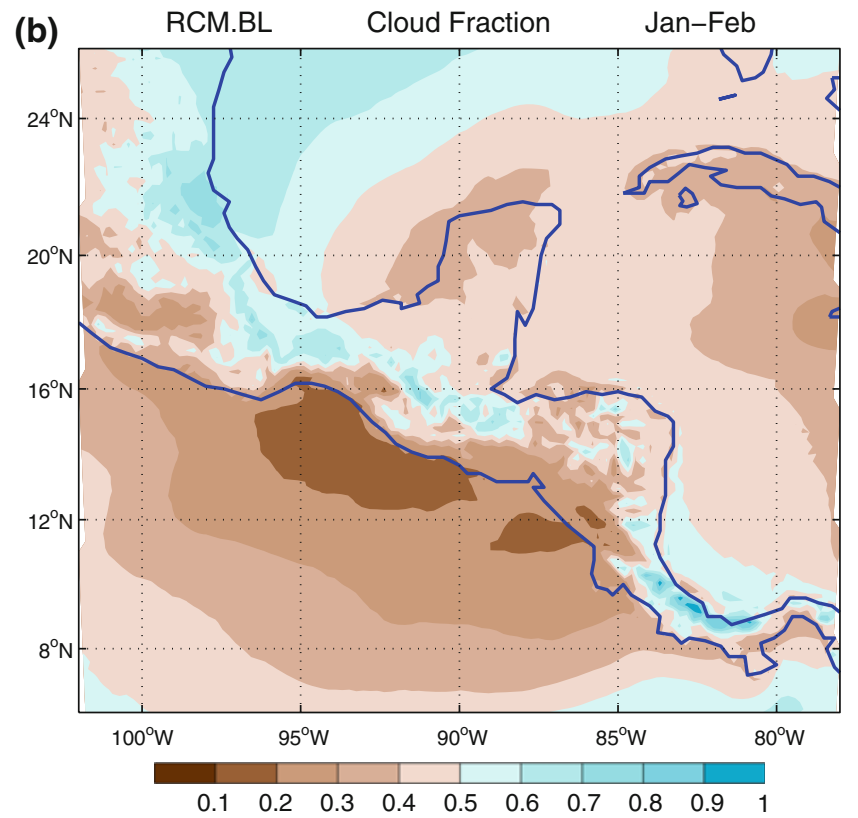

Fig. 12 a Thirty year mean non-convective PRCP fraction as simulated by the RCM and 30 year mean of fractional cloud-cover as simulated by $\mathbf{b}$ the RCM and $\mathbf{c}$ the GCM for the months of Jan-

shown in Fig. 15, which shows amplified warming in the middle/upper troposphere relative to surface values. Warming increases from about $3^{\circ} \mathrm{C}$ at the surface to over $5^{\circ} \mathrm{C}$ in the upper troposphere. Latitudes southward of $10^{\circ} \mathrm{S}$ have Andean peaks over $4,000 \mathrm{~m}$, which will likely experience warming of about $4.5^{\circ} \mathrm{C}$. Central America, where model elevation reaches about $3,000 \mathrm{~m}$ is likely to experience warming of about $4^{\circ} \mathrm{C}$ in both seasons. These projections are consistent with those discussed in Bradley et al. (2004) and Hansen et al. (2002).

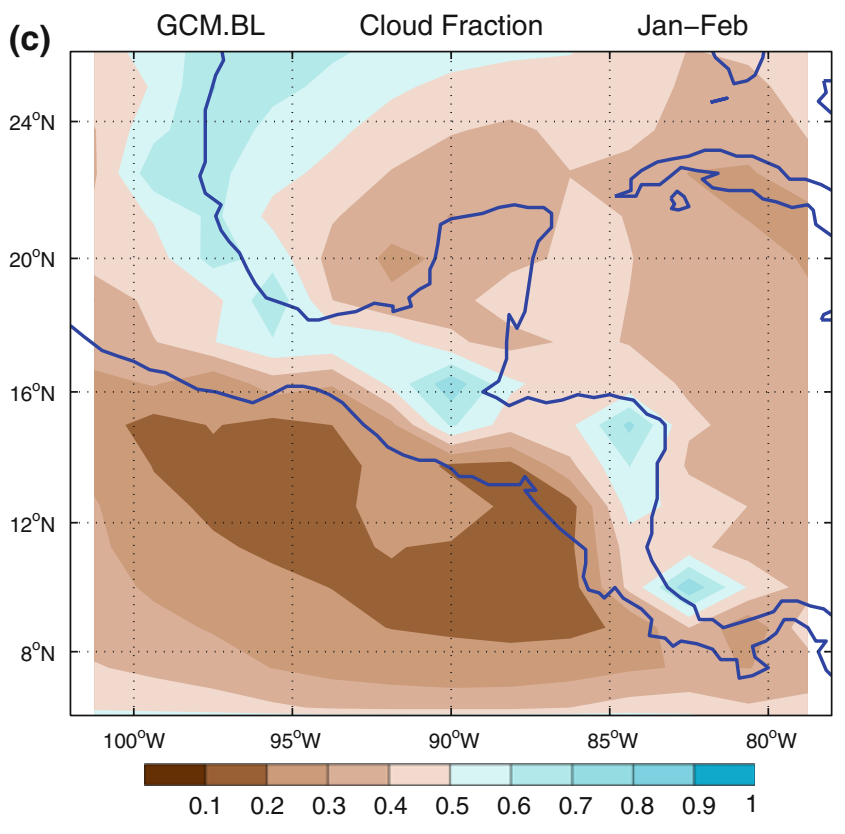

Feb. The CLLJ has maximum values during these months resulting in increased moisture flux reaching Central America

\section{Hydrological response to climate change}

\subsection{Precipitation response}

The modern-day wet and dry season precipitation climatologies as simulated by the GCM and the RCM are discussed in Sect. 3.2 and are depicted in Fig. 5. Projected changes in these precipitation patterns under the SRES A2 scenario are shown in Fig. 16. Similar to the case of model validation (Sect. 3), the PDFs are used here to quantify 
Fig. 13 a First EOF of the mean annual SAT field over land and $\mathbf{b}$ its corresponding principal component, which shows strong correlation with the ENSO 3.4 index
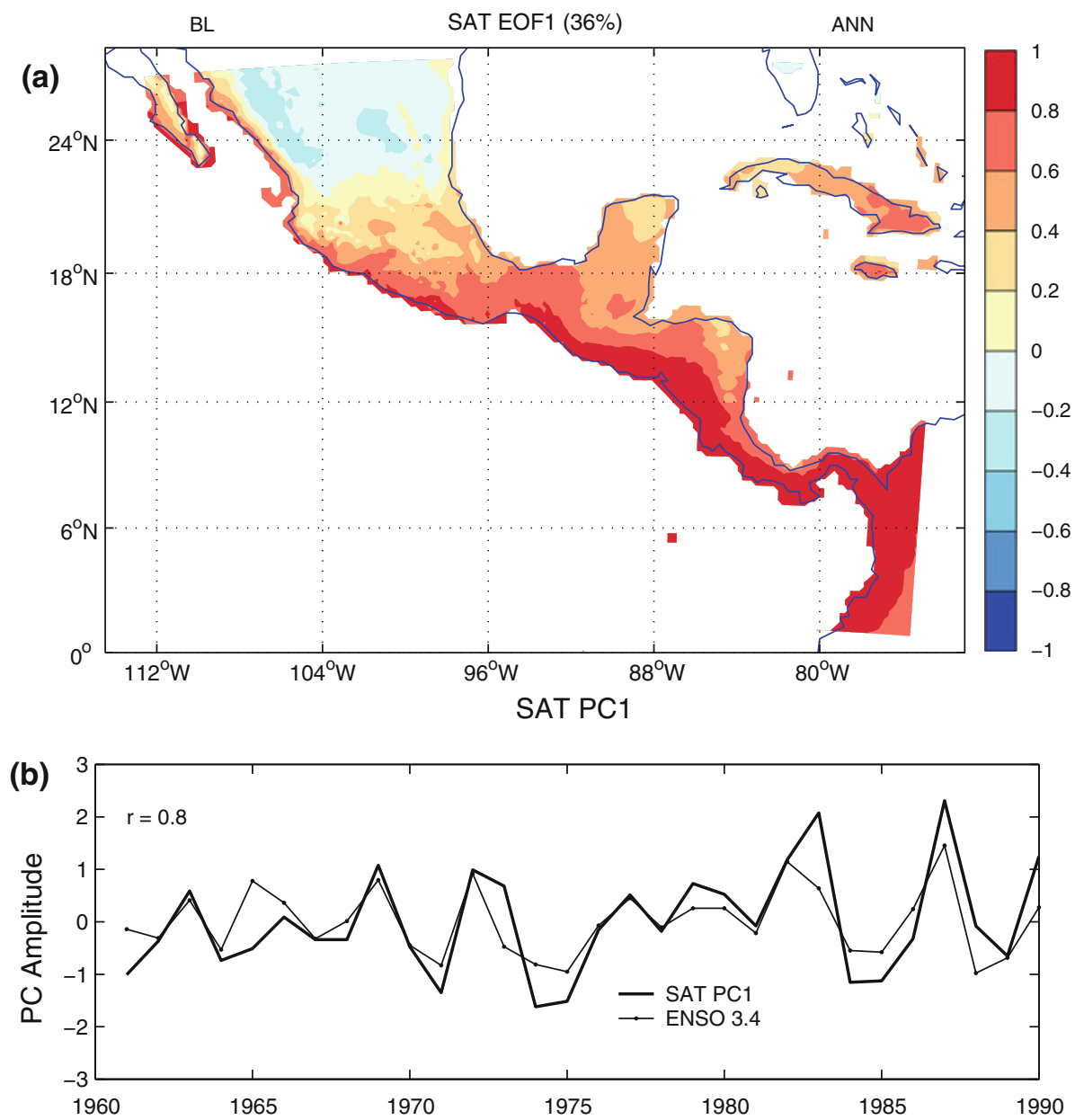

projected changes in the mean $(\mu)$ and variability $(2 \sigma)$ of the distribution of seasonal precipitation. The modern-day and future scenario PDFs for six regions (Fig. 7) for the GCM and RCM are shown in Fig. 9 and changes projected by the RCM are tabulated in Table 5 .

The difference between the RCM.A2 and baseline wet season climatology (Fig. 16a) shows both increases and decreases in mean precipitation in the region. The IAS region, central American landmass, and the eastern Pacific warm pool region are projected to experience a reduction in precipitation under the future scenario. A southward shift in the position of the ITCZ in the Pacific and an increase in the ITCZ precipitation is also noted in the future scenario simulations. Due to this southward shift of the ITCZ band, the region along the coast of Central America will experience a decrease in precipitation in the wet season, which, in general, is associated with an increase in the MSLP in the Caribbean. A large decrease in precipitation can be seen in the wet season over land in most of Mexico and the CAM region. Large decreases are predicted for eastern Mexico (region 2; -29.5\%), and southern Mexico and the Yucatan Peninsula (region 4; -39\%). Central American regions along the Pacific coast (regions 3 and 5) are projected to experience a decrease in rainfall by about 16 and $25 \%$ respectively relative to modern-day values. Projected changes in the widths of the PDFs suggest a decrease in the wet season precipitation variability in most of Central America and Mexico. Regions along the Caribbean coast of Central America $(4,6)$ show large decreases in precipitation variability compared to other regions.

The difference between mean dry season climatology of the baseline and SRES A2 runs (Fig. 16b) shows both small increases and decreases in precipitation in the region. The Caribbean Sea and the Central American landmass are projected to receive less precipitation in the future scenario than the modern-day values in the dry season. This decrease in precipitation is accompanied by a decrease in MSLP in the Caribbean Sea. The dry season PDFs for regions on the Pacific side (1, 3, and 5) are positively skewed in comparison to Caribbean regions $(2,4,6)$ suggesting less PRCP on the Pacific side than the Caribbean side (Fig. 7). This is a result of orographic uplift of northeasterly/easterly trade winds as they encounter the Cordillera resulting in orographic PRCP along the Caribbean slopes of the region. The dry season mean 

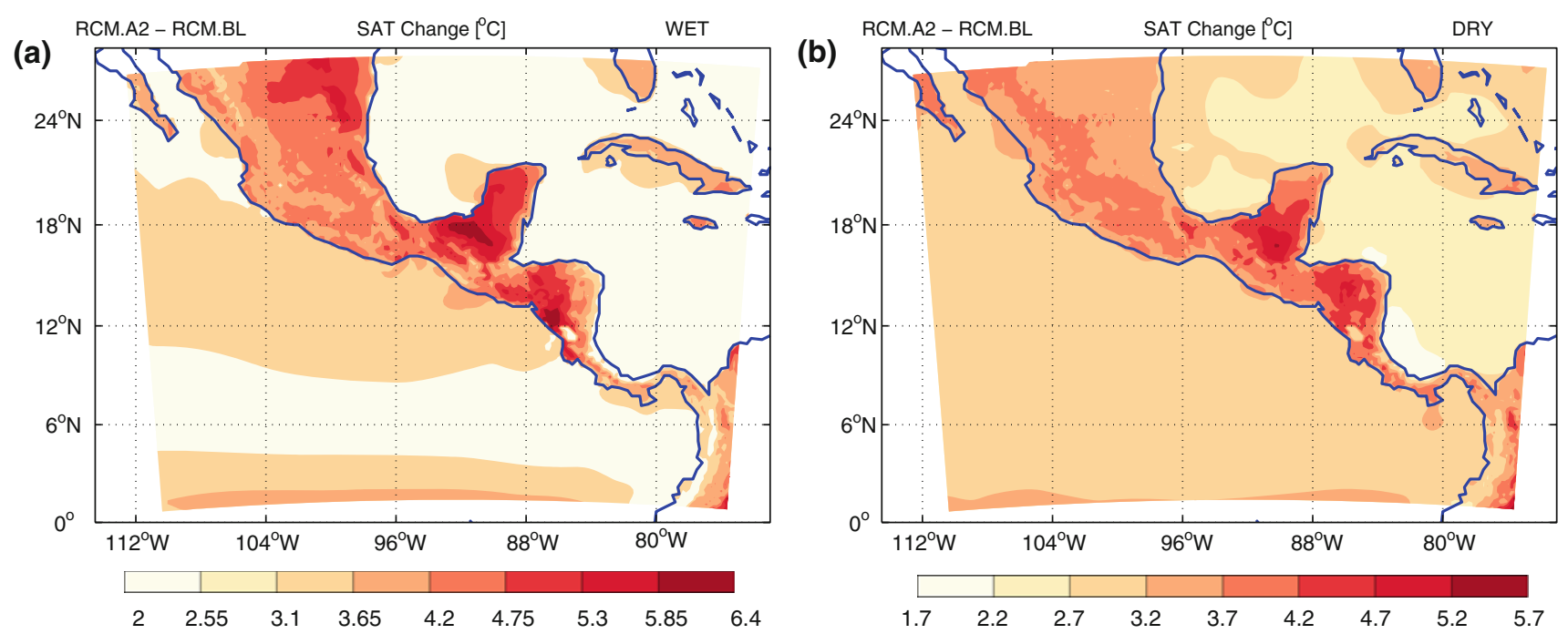

Fig. 14 Surface air temperature projections (RCM.A2-RCM.BL) for a wet (May-Oct) b dry (Nov-Apr) seasons. Limits of the color bars roughly denote minimum to maximum changes simulated within the model domain

Table 4 Changes projected by the RCM in seasonal SAT mean $(\mu)$ and variability $(\sigma$; standard deviation) under the SRES A2 scenario for six regions defined in Fig. 7

\begin{tabular}{llllll}
\hline & \multicolumn{2}{l}{ Wet season } & & \multicolumn{2}{l}{ Dry season } \\
\cline { 2 - 3 } \cline { 5 - 6 } & $\mu_{\text {proj }}\left({ }^{\circ} \mathrm{C}\right)$ & $\sigma_{\text {proj }}(\%)$ & & $\mu_{\text {proj }}\left({ }^{\circ} \mathrm{C}\right)$ & $\sigma_{\text {proj }}(\%)$ \\
\hline 1 & 4.2 & 29 & 3.7 & 8 \\
2 & 4.7 & 25 & 3.4 & 10 \\
3 & 4.2 & 82 & 3.6 & 13 \\
4 & 4.7 & 62 & 3.9 & 15 \\
5 & 4.3 & 71 & 3.8 & 18 \\
6 & 3.1 & 74 & 3.2 & 49 \\
\hline
\end{tabular}

precipitation is not only higher for regions on the Caribbean side but also increases as one moves southward from Mexico to Panama. The largest decrease in PRCP in the dry season is predicted on the Pacific (region $5 ;-14 \%$ ) and the Caribbean (region 6; -24\%) slopes of Costa Rica and Panama. A decrease in precipitation variability is also large $(-16$ and $-21 \%)$ for these regions. The projected changes for other regions are not statistically significant.

Annual cycles of precipitation for six regions for the baseline and scenario runs are depicted in Fig. 10 and projected changes in the annual cycle of precipitation under the SRES A2 scenario are shown in Fig. 17. Maximum reduction in precipitation is experienced during the wet season in all regions, except for region 6 , which shows largest reduction during the dry season months. Figure 10 suggest no substantial change in the shape of the annual cycle in most of Central America and Mexico except for regions 1 and 6. The future annual cycle of PRCP in western Mexico (region 1) has two peaks under the A2 scenario. On the Atlantic side of Costa Rica and Panama (region 6), there is a clear change in the shape of the annual cycle where the bimodal structure disappears in the simulation of future conditions. An examination of the change in the length of the wet or dry seasons would require daily PRCP data, which were unavailable in this case.

\subsection{Humidity and the Caribbean low-level jet}

Changes in precipitation are closely linked to changes in atmospheric humidity, soil moisture, evaporation, cloud cover, outgoing longwave radiation among other parameters. The spatial pattern of change in the cloud cover and the outgoing longwave radiation resemble the spatial pattern of change in precipitation in both seasons where a decrease (increase) in precipitation is related to a decrease (increase) in cloud cover and an increase (decrease) in the longwave radiation. A decrease in soil moisture predicted by the RCM under the A2 scenario mimics the projected change in precipitation and therefore not shown here. The specific humidity at $1.5 \mathrm{~m}$ (SHUM) and relative humidity at $1.5 \mathrm{~m}$ (RHUM) show coherent changes in their annual cycles in the future (Fig. 17). Column mean specific humidity (SHCM) over Central America increases under the SRES A2 scenario over the entire model domain in both seasons. Most of the moisture increase is in the lower troposphere from the surface to about $500 \mathrm{mb}$ level. The spatial pattern of increase in the SHCM does not resemble the spatial pattern of change in evaporation (not shown), particularly over the Gulf of Mexico and the Caribbean Sea. This suggests that moisture advection by trade winds, by the Caribbean Low-Level Jet in particular, from the tropical Atlantic is necessary to explain the SHCM increase. The RCM successfully simulated the position, 
Fig. 15 Projected changes in mean annual free air temperatures along a transect from Mexico to Panama as a function of altitude

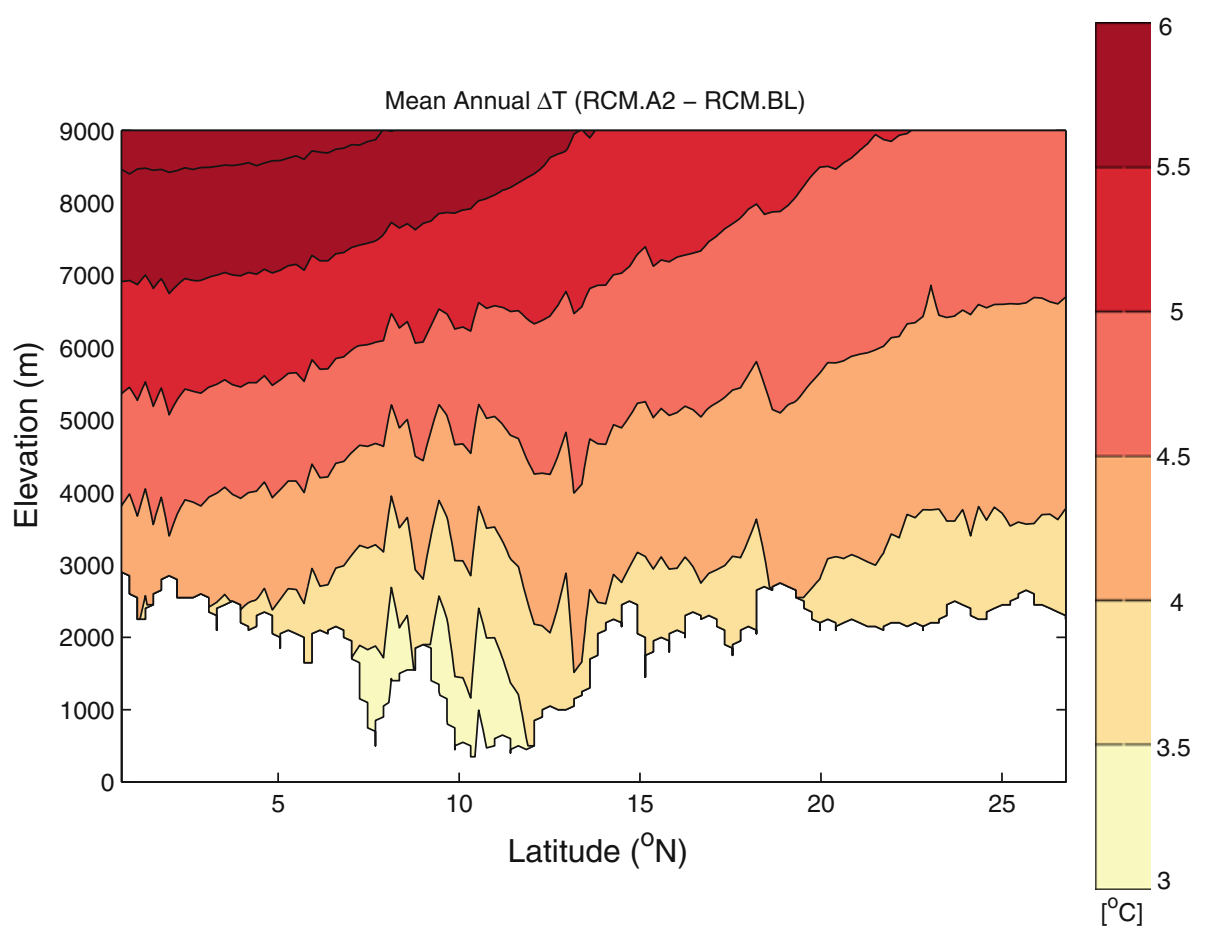

Table 5 Changes projected by the RCM in seasonal precipitation mean $(\mu)$ and variability ( $\sigma$; standard deviation) under the SRES A2 scenario for six regions defined in Fig. 7

\begin{tabular}{lccccc}
\hline & \multicolumn{2}{l}{ Wet season } & & \multicolumn{2}{c}{ Dry season } \\
\cline { 2 - 3 } \cline { 5 - 6 } & $\mu_{\text {proj }}(\%)$ & $\sigma_{\text {proj }}(\%)$ & & $\mu_{\text {proj }}(\%)$ & $\sigma_{\text {proj }}(\%)$ \\
\hline 1 & -0.5 & -11 & & -8.1 & -3 \\
2 & -29.5 & 5 & 7.6 & -2 \\
3 & -16.2 & 9 & 7.8 & 45 \\
4 & -38.6 & 5 & & -8.6 & 5 \\
5 & -24.7 & 25 & & -13.6 & -16 \\
6 & -8.4 & 2 & & -23.8 & -21 \\
\hline
\end{tabular}

magnitude and the annual cycle of the CLLJ as discussed earlier. The intensity of the CLLJ (or the trade winds in the Caribbean) is dependent on the strength of the NASH (Muñoz et al. 2008; Wang 2007; Wang and Lee 2007). Under the A2 scenario, a strengthening of the NASH results in an increase in the intensity of the CLLJ during the wet season. The CLLJ is stronger during the wet season by about $2 \mathrm{~m} / \mathrm{s}$ (about $15 \%$ increase; Fig. 18a) whereas the dry season experiences very little or no change. The change in the annual cycle of specific humidity at $925 \mathrm{mb}$ shows (Fig. 18b) a near constant increase in the amount of moisture throughout the year in the scenario run. Due to an increase in both the CLLJ speed and specific humidity at $925 \mathrm{mb}$, the moisture transport into the Central American region through the Caribbean Sea is predicted to increase in the future (Fig. 18c). It is important to note that, most of
Central America will experience drier conditions in spite of this increase in the moisture reaching the region in the future.

\section{Conclusions and discussion}

A number of methods are used to evaluate the RCM's skill in simulating surface air temperature and precipitation. A combination of the EOF analysis and cluster analysis on RCM temperature and precipitation data produced clusters that resemble large scale climate regimes observed in Mexico and Central America. These clusters were used to quantify model biases for different regions within the model domain. In the case of surface air temperature, the RCM shows a cold bias with respect to CRU (that increases with elevation) and a warm bias with respect to the NARR data. Lapse rate calculations for a variety of data sets including the GHCN and WorldClim station data suggest that although CRU has a warm bias at high elevations, it does not fully explain the cold bias seen in the RCM. The model lapse rate for high elevations (greater than $1000 \mathrm{~m}$ considered here) is steeper than all the comparison data sets suggesting that the model indeed has a cold bias. One of the candidates for the systematic cold bias in PRECIS could be the driving GCM. The third generation Hadley Centre atmospheric model (HadAM3), which provides boundary conditions for PRECIS has been tested thoroughly for its performance (Pope et al. 2000). HadAM3 results compare well with the observed mean climate and 

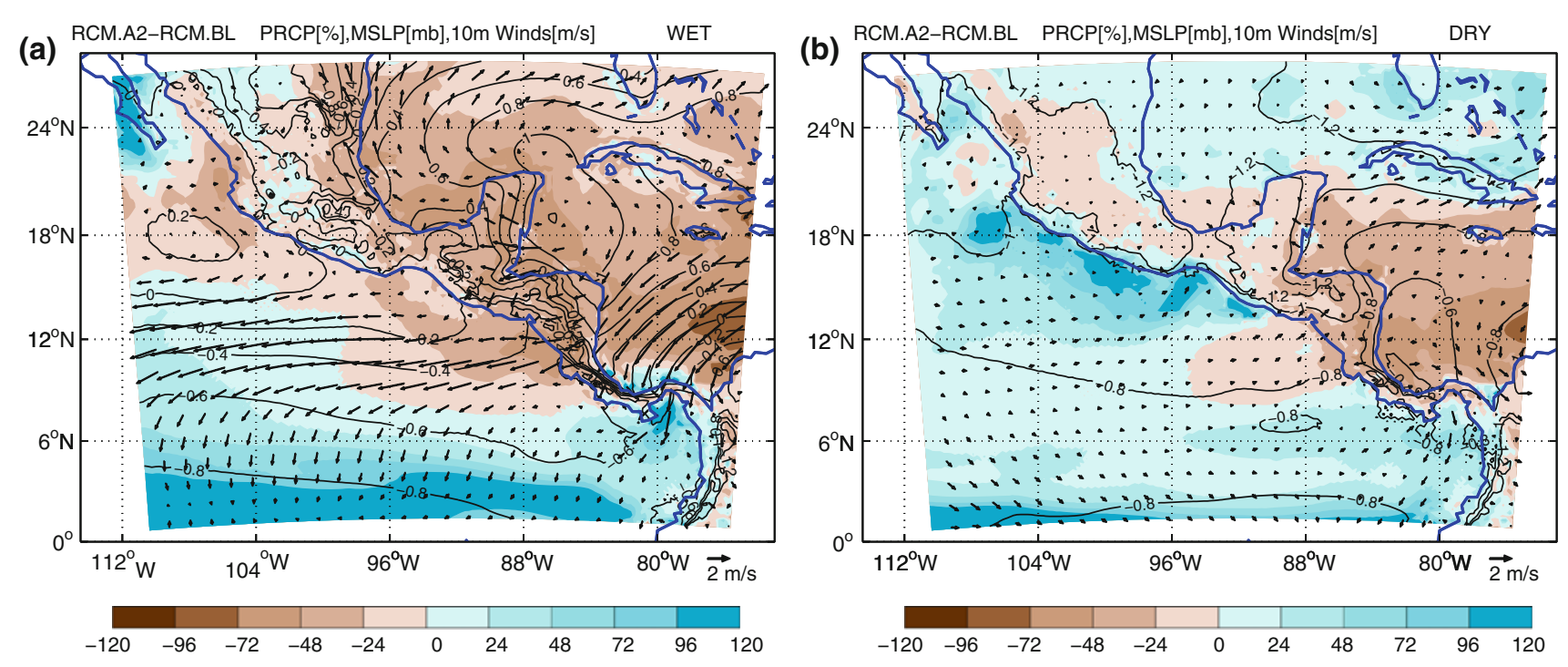

Fig. 16 Projected change in PRCP (colors, \% change with respect to RCM.BL), MSLP (contours in mb) and $10 \mathrm{~m}$ winds (m/s). Percentage change within $\pm 20 \%$ is not significant at the $95 \%$ significance level

Fig. 17 Projected changes (RCM.A2-RCM.BL) in annual cycles of precipitation, $1.5 \mathrm{~m}$ specific humidity and $1.5 \mathrm{~m}$ relative humidity for six regions shown in Fig. 7. The projected change in PRCP is calculated from annual cycles of precipitation for the RCM baseline (RCM.BL; thin colored) and the SRES A2 scenario (RCM.A2; thick colored) shown in Fig. 10

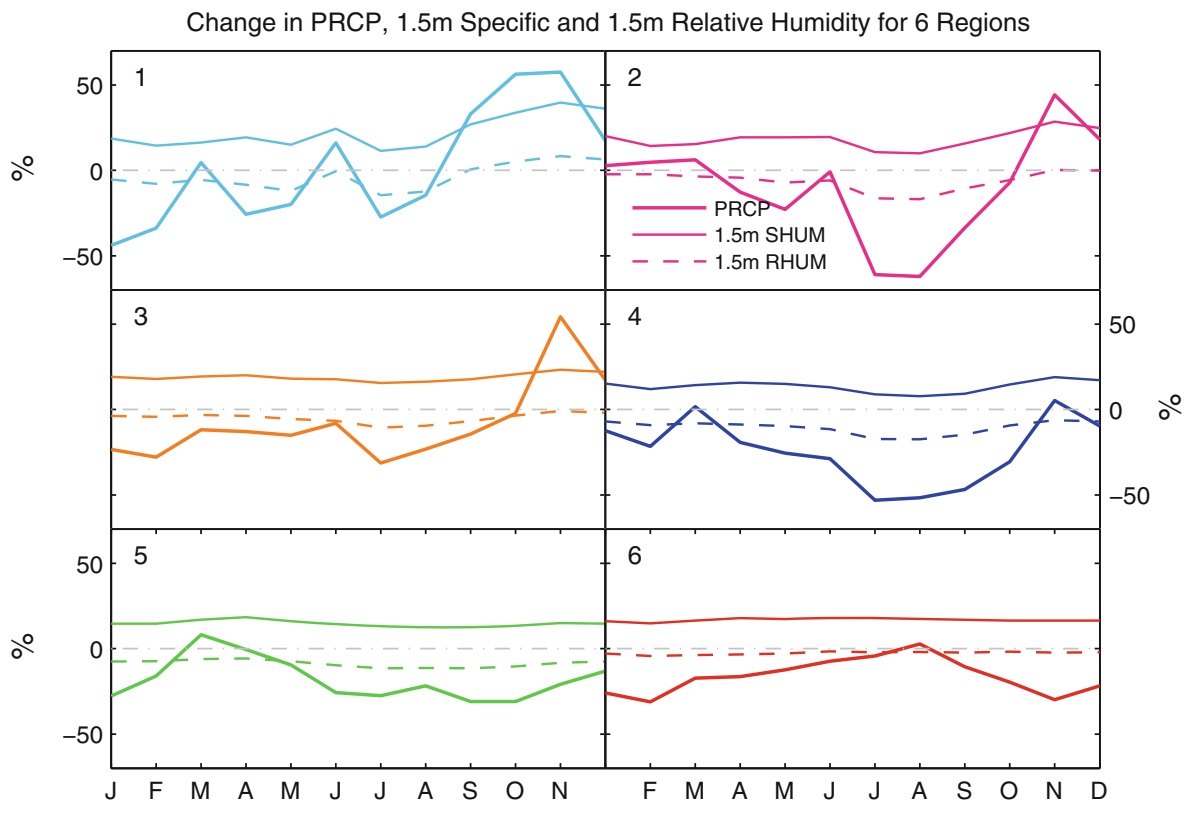

also with other climate models in the Atmospheric Model Intercomparison Project (AMIP; Gates et al. 1999). In the tropics, HadAM3 performs better than the AMIP ensemble mean throughout the troposphere. Overall, HadAM3 has been shown to produce a good simulation of the presentday climate when forced with observed sea surface temperatures (Pope et al. 2000), which is how it is employed in the validation phase of this study. Nevertheless, a cold bias at all tropospheric levels in the tropics is detected in HadAM3 simulations (Pope et al. 2000). There is also a dry bias in the tropical middle troposphere that could result in cold bias in temperature at those levels. Earlier PRECIS studies (Urrutia and Vuille 2009; Akhtar et al. 2008) driven by HadAM3 boundary conditions notice an increased cold bias at higher elevations in other parts of the world. The elevation dependency of the model bias might be due to inconsistencies in the CRU data set at high elevation gridpoints. New et al. $(1999,2000)$ conclude that SAT uncertainties are largest over areas with poor station coverage and high spatial variability. They note that stations at higher elevations may show warm bias due to the dominance of stations at lower elevations, which is true for CRU SAT data in Mexico and Central America. Model cold bias is, however, not constant across the region and seasons. The bias is higher in the wet season and lower in the dry season. The cold bias is particularly high in the highlands 


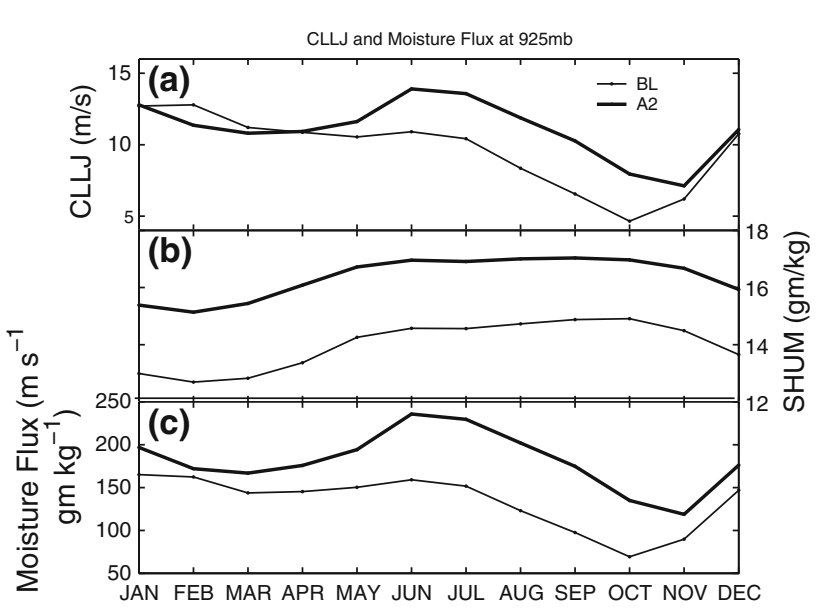

Fig. 18 Annual cycle of a CLLJ $\left(-\mathrm{u}_{925}\right)$, b specific humidity at 925 $\mathrm{mb}\left(\mathrm{q}_{925}\right)$ and $\mathbf{c}$ moisture flux $\left((-\mathrm{u} \times \mathrm{q})_{925}\right)$ for a cross section in the Caribbean Sea at $76.6^{\circ} \mathrm{W}$

of Mexico where precipitation is overestimated in the wet season. Excess precipitation in the region may result in anomalously wet soils, which would lead to low sensible heat flux and therefore lower surface temperatures. But a similar mechanism can not explain the cold bias in Central America, which occurs in spite of simulated precipitation being severely underestimated in this region.

Although there are considerable differences in the precipitation amounts between the model and observations, the RCM successfully captured various precipitation patterns in the CAM region and showed improvements over the GCM. The RCM amounts are smaller (larger) than GPCC precipitation in the wet (dry) season. A dry precipitation bias in the wet season and a wet bias in the dry season indicate that the RCM does not fully capture precipitation variability in the region. The current suite of coupled global climate models (PCMDI models) do have difficulties in realistically simulating regional precipitation patterns and their temporal variations (Dai 2006). Most global climate models underestimate precipitation in Central America (Rauscher et al. 2008) partly due to underestimation of SSTs and coarse horizontal resolution. The driving GCM, HadAM3P, severely underestimates precipitation in the wet season as well. It has been shown that the Hadley Centre global model, HadCM3 underestimated cloud cover over most of the globe, especially over lowlatitude oceans (Martin et al. 2004), which resulted in underestimation of precipitation. The RCM shows dry bias mainly in the late wet season when some fraction of total precipitation comes from tropical cyclones (Rodgers et al. 2001; Jian and Zipser 2010). The model's inability to simulate cyclones realistically may explain a part of the dry bias seen in the late wet season. But, the daily model output is unavailable to test this claim. In general, models tend to overestimate the frequency of light precipitation and underestimate the intensity of heavy precipitation over land (Mearns et al. 1995; Seth et al. 2004) that could result in the PDFs of simulated PRCP seen here. Despite the difficulties in simulating PRCP amounts correctly, the regional model certainly shows improvements over the predictions by the GCMs in the PCMDI data sets presented by Rauscher et al. (2008). The bimodal nature of the annual cycle of precipitation is one of the unique features of this region and is well captured by the RCM. The structure and variations in the Caribbean low-level jet are also well simulated by the regional model. The SAT variability in Central America is tightly coupled to the ENSO variations in the eastern equatorial Pacific and the interannual variability of simulated annual SAT is strongly correlated with the Pacific SST in most of Central America since the baseline run is driven by the observed SST.

The IPCC models projected global temperature increase of $3.4^{\circ} \mathrm{C}$ at the end of the 21 st century under the SRES A2 scenario (Solomon et al. 2008). The RCM projected warming in this study for Mexico and Central America is greater than the global temperature increase. Warming in the wet season (over $4^{\circ} \mathrm{C}$ ) is higher than that in the dry season $\left(3-4^{\circ} \mathrm{C}\right)$ in most of Central America except for the Caribbean coasts of Costa Rica and Panama. The Yucatan Peninsula shows maximum warming within the model domain in both wet $\left(4.7^{\circ} \mathrm{C}\right)$ and dry $\left(3.9^{\circ} \mathrm{C}\right)$ seasons. In the highlands of Nicaragua and Costa Rica, the future SAT distributions lie completely outside the present-day distributions, which shows that warmest temperatures in the baseline run are lower than the coldest temperatures in the scenario run. In addition to warming, the RCM also predicts an increase in the variability of land SATs in the region, which could be due to increased SST variability in the equatorial Pacific. An increase in the atmospheric water vapor in the future and the associated increase in the latent heat release results in a decreased moist-adiabatic lapse rate and a higher increase in temperatures in the free troposphere (Santer et al. 2005, 2008). Amplified warming at higher elevation seen in PRECIS simulations and noted in the previous studies (Bradley et al. 2004; Karmalkar et al. 2008) and related precipitation changes may have serious consequences for ecosystems in the area.

The ENSO has a near-simultaneous effect on Central American temperature and precipitation. In general, during the warm (cold) phase of the ENSO, positive (negative) SAT anomalies and negative (positive) PRCP anomalies are observed all across Central America. With the help of an EOF analysis, it was shown that climate of the Pacific slopes of Central America is linked strongly to the ENSO variations in the eastern equatorial Pacific. Furthermore, Pounds et al. (1999) demonstrated that the dry-season mist frequency, a crucial source of water in the cloud forests of 
Costa Rica, is negatively correlated to SSTs in the equatorial Pacific and has declined dramatically with an increase in the SSTs since the mid-1970s affecting amphibian populations. Warming of the Pacific SSTs in the SRES A2 scenario is over $3^{\circ} \mathrm{C}$, which is far greater than the present-day positive anomalies (about $1^{\circ} \mathrm{C}$ ) during the warm phase of ENSO. Besides, the drying pattern in most of Central America under the A2 scenario is very similar to the dry anomalies observed during the El Niño events (Neelin et al. 2003), which leads us to speculate that present-day El Niño-like conditions might be the norm in the future. The current suite of climate models do face difficulty in simulating ENSO (AchutaRao and Sperber 2006; Davey et al. 2002) and therefore disagree on its future behavior. Nonetheless, considering impacts of present-day warm anomalies on Central America, future warming of $3-4^{\circ} \mathrm{C}$ and changes in magnitude and variability of precipitation may pose a serious threat to biodiversity, water resources and related socio-economic sectors in Mexico and Central America.

To our knowledge, there have been very few studies focusing on climate change in Mexico and Central America. Results presented here are based on one set of GCMRCM experiment and should be further improved using multiple GCM-RCM configurations. PRECIS can now be driven by a number of reanalysis products and the ECHAM GCM (in addition to HadAM3P), which are required to fully understand the origin of PRECIS biases. Projections from ensemble of RCMs will also help us gain confidence in regional climate change projections presented in this study. In future studies, daily data should be used in order to fully understand the utility of a regional model over coarse resolution GCMs and to study changes in climate extremes under the future scenario. Nonetheless, this study demonstrates the importance of using dynamical downscaling technique and highlights the difficulty of validating climate model in climate change studies in regions of high relief.

Acknowledgments This research was supported by the Office of Science (BER), U.S. Department of Energy. We thank the anonymous reviewers for their constructive comments on our manuscript.

\section{References}

AchutaRao K, Sperber KR (2006) ENSO simulation in coupled ocean-atmosphere models: are the current models better? Clim Dyn 27(1):1-15. doi:10.1007/s00382-006-0119-7

Adams DK, Comrie AC (1997) The north American monsoon. Bull Amer Meteor Soc 78:2197-2213

Akhtar M, Ahmad N, Booij MJ (2008) The impact of climate change on the water resources of Hindukush-Karakorum-Himalaya region under different glacier coverage scenarios. J Hydrol 355(1-4):148-163. doi:10.1016/j.jhydrol.2008.03.015
Alfaro EJ (2002) Response of air surface temperatures over Central America to oceanic climate variability indices. Invest Marin 30:86-87

Amador JA (1998) A climatic feature of the tropical Americas: the trade wind easterly jet. Tópicos Meteorológicos y Oceanográficos 5(2):91-102

Amador JA (2008) The Intra-Americas sea low-level jet: overview and future research. Annal NY Acad Sci 1146(1):153-188

Anchukaitis KJ, Evans MN (2010) Tropical cloud forest climate variability and the demise of the Monteverde golden toad. PNAS 107(11):5036-5040. doi:10.1073/pnas.0908572,107

Bradley RS, Keimig FT, Diaz HF (2004) Projected temperature changes along the American Cordillera and the planned GCOS network. Geophys Res Lett 31(16). doi:10.1029/2004GL020,229

Bradley RS, Vuille M, Diaz HF, Vergara W (2006) Threats to water supplies in the tropical Andes. Science 312(5781):1755-1756

Bruijnzeel LA, Proctor J (1993) Hydrology and biogeochemistry of tropical montane cloud forests. Tropical Montane Cloud Forests symposium proceedings, San Juan, Puerto Rico, May, pp 25-46

Buytaert W, Vuille M, Dewulf A, Urrutia R, Karmalkar AV, Celleri R (2010) Uncertainties in climate change projections and regional downscaling in the tropical Andes: implications for water resources management. Hydrol Earth Syst Sci 14:1247-1258. doi:10.5194/hess-14-1247-2010

Caldwell P, Chin SH, Bader DC, Bala G (2009) Evaluation of a WRF dynamical downscaling simulation over California. Clim Change 95:499-521. doi:10.1007/s10,584-009-9583-5

Christensen JH, coauthors (2007) Regional climate projections. Climat change 2007: the physical science basis. Contribution of WGI to the IPCC AR4. In: Solomon S et al (eds) Cambridge University Press, Cambridge

Clark KL, Lawton RO, Butler P (1999) The physical environment of Monteverde. Oxford University Press, Oxford

Collins JP, Storfer A (2003) Global amphibian declines: sorting the hypotheses. Divers Distrib 9(2):89-98

Cox PM, Betts RA, Bunton CB, Essery RLH, Rowntree PR, Smith J (1999) The impact of new land surface physics on the GCM simulation of climate and climate sensitivity. Clim Dyn 15(3):183-203

da Rocha RP, Morales CA, Cuadra SV, Ambrizzi T (2009) Precipitation diurnal cycle and summer climatology assessment over South America: an evaluation of regional climate model version 3 simulations. J Geophy Res 114:D10-108. doi: 10.1029/2008JD010,212

Dai A (2006) Precipitation characteristics in eighteen coupled climate models. J Clim 19(18):4605-4630

Davey M, Huddleston M, Sperber K, Braconnot P, Bryan F, Chen D, Colman R, Cooper C, Cubasch U, Delecluse P et al (2002) STOIC: a study of coupled GCM climatology and variability in tropical ocean regions. Clim Dyn 18:403-420. doi:10.1007/ s00382-001-0188-6

Diaz HF, Eischeid JK, Duncan C, Bradley RS (2003) Variability of freezing levels, melting season indicators, and snow cover for selected high- elevation and continental regions in the last 50 years. Clim Change 59(1-2):33-52

Duran-Quesada AM, Gimeno L, Amador JA, Nieto R (2010) Moisture sources for Central America: Identification of moisture sources using a lagrangian analysis technique. J Geophys Res 115:D05-103. doi:10.1029/2009JD012,455

Enfield DB (1996) Relationships of inter-American rainfall to tropical Atlantic and Pacific sst variability. Geophys Res Lett 23(23): 3305-3308

Enfield DB, Elfaro EJ (1999) The dependence of Caribbean rainfall on the interaction of the tropical Atlantic and Pacific oceans. J Clim 12(7):2093-2103 
Enfield DB, Mayer DA (1997) Tropical Atlantic sea surface temperature variability and its relation to El Niño Southern Oscillation. J Geophys Res Ocean 102(C1)

Gamble DW, Curtis S (2008) Caribbean precipitation: review, model and prospect. Prog Phys Geo 32(3). doi:10.1177/0309 133308096027

Gasner MR, Jankowski JE, Ciecka AL, Kyle KO, Rabenold KN (2010) Projecting the local impacts of climate change on a Central American montane avian community. Biol Conserv 143(5):1250-1258. doi:10:1016/j.biocon.2010.02.034

Gates WL, Boyle JS, Covey C, Dease CG, Doutriaux CM, Drach RS, Fiorino M, Gleckler PJ, Hnilo JJ, Marlais SM et al (1999) An overview of the results of the atmospheric model intercomparison project (AMIP I). Bull Am Meteorol Soc 80(1):29-55

Giannini A, Kushnir Y, Cane MA (2000) Interannual variability of caribbean rainfall, ENSO, and the Atlantic ocean. J Clim 13(2):297-311

Giannini A, Kushnir Y, Cane MA (2001) Seasonality in the impact of ENSO and the North Atlantic High on Caribbean rainfall. Phys Chem Earth Part B 26(2):143-147

Giorgi F (2006) Climate change hot-spots. Geophys Res Lett 33(8). doi:10.1029/2006GL025,734

Giorgi F, Francisco R (2000) Uncertainties in regional climate change prediction: a regional analysis of ensemble simulations with the HADCM2 coupled AOGCM. Clim Dyn 16(2):169-182

Gordon C, Cooper C, Senior CA, Banks H, Gregory JM, Johns TC, Mitchell JFB, Wood RA (2000) The simulation of SST, sea ice extents and ocean heat transports in a version of the Hadley Centre coupled model without flux adjustments. Clim Dyn 16(2):147-168

Hansen J, Sato M, Nazarenko L, Ruedy R, Lacis A, Koch D, Tegen I, Hall T, Shindell D, Santer B et al (2002) Climate forcings in Goddard Institute for Space Studies SI2000 simulations. J Geophys Res 107(10.1029)

Hasternath S (1991) Climate dynamics of the tropics. Kluwer, The Netherlands

Hernandez JL, Srikishen J, Erickson DJI, Oglesby R, Irwin D (2006) A regional climate study of Central America using the MM5 modeling system: results and comparison to observations. Int $\mathbf{J}$ Climatol 26(15):2161-2179

Hijmans RJ, Cameron SE, Parra JL, Jones PG, Jarvis A (2005) Very high resolution interpolated climate surfaces for global land areas. Int J Climatol 25:1965-1978

Jiang H, Zipser EJ (2010) Contribution of Tropical Cyclones to the Global Precipitation from Eight Seasons of TRMM Data: Regional, Seasonal, and Interannual Variations. J Clim 23:1526-1543. doi:10.1175/2009JCLI3303.1

Jones RG, Noguer M, Hassel DC, Hudson D, Wilson SS, Jenkins GJ, Mitchell JFB (2004) Generating high resolution climate change scenarios using PRECIS. Met Office, Hadley Center, Exeter, $\mathrm{UK}, \mathrm{p} 40$

Karmalkar AV, Bradley RS, Diaz HF (2008) Climate change scenario for Costa Rican montane forests. Geophys Res Lett 35(11):L11-702

Kim J, Lee JE (2003) A multiyear regional climate hindcast for the western United States using the mesoscale atmospheric simulation model. J Hydrometeorol 4(5):878-890

Lips KR, Diffendorfer JRM III, Sears MW (2008) Riding the wave: reconciling the roles of disease and climate change in amphibian declines. PLoS Biol 6(3):e72

MacQueen JB (1967) Some methods for classification and analysis of multivariate observations. Proceedings of 5th Berkeley symposium on mathematical statistics and probability, vol 1. University of California Press, Berkeley, pp 281-297

Magaña V, Caetano E (2005) Temporal evolution of summer convective activity over the Americas warm pools. Geophys Res Lett 32(2):L02-803
Magaña V, Amador JA, Medina S (1999) The midsummer drought over Mexico and Central America. J Clim 12(6):1577-1588

Martin GM, Dearden C, Greeves C, Hinton T, Inness P, James P, Pope VD, Ringer MA, Stratton RA, Yang GY (2004) Evaluation of the atmospheric performance of HadGAM/GEM1 (Hadley Centre Technical Note 54)

Mearns LO, Gutowski WJ, Jones R, Leung LY, McGinnis S, Nunes AMB, Qian Y (2009) A regional climate change assessment program for North America. EOS 90(36):311-312

Mearns LO, Giorgi F, McDaniel L, Shields C (1995) Analysis of daily variability of precipitation in a nested regional climate model: comparison with observations and doubled $\mathrm{CO}_{2}$ results, Global Planet. Change 10:55-278

Mesinger F, Co-authors (2006) North American Regional Reanalysis, Bull Amer Meteor Soc 87:343-360

Mestas-Nuñez AM, Enfield DB (2001) Eastern equatorial pacific SST variability: ENSO and non-ENSO components and their climatic associations. J Clim 14(3):391-402

Miller K, Chang E, Johnson N (2001) Defining common ground for the Mesoamerican biological corridor. World Resources Institute

Mitchell TD, Jones PD (2005) An improved method of constructing a database of monthly climate observations and associated highresolution grids. Int J Climatol 25(6):693-712

Muñoz E, Busalacchi AJ, Nigam S, Ruiz-Barradas A (2008) Winter and summer structure of the Caribbean low-level jet. J Clim 21(6): 1260-1276

Myers N, Tucker R (1987) Deforestation in Central America: Spanish legacy and North American consumers. Environ Rev 11(1):55-71

Myers N, Mittermeier RA, Mittermeier CG, da Fonseca GAB, Kent J (2000) Biodiversity hotspots for conservation priorities. Nature 403(6772):853-858

Nakicenovic N, Alcamo J, Davis G, de Vries B, Fenhann J, Gaffin S, Gregory K, Grbler A, Jung TY, Kram T, et al (2000) Special Report on Emissions Scenarios (SRES). Working group III of the Intergovernmental panel on climate change (IPCC), p 595. Cambridge University Press, Cambridge. Available at http://www.grida. no/climate/ipcc/emission/index.htm..

Neelin JD, Chou C, Su H (2003) Tropical drought regions in global warming and El Niño teleconnections. Geophys Res Lett 30(24):2275

New M, Hulme M, Jones P (1999) Representing twentieth-century space-time climate variability. part i: Development of a 1961-90 mean monthly terrestrial climatology. J Clim 12(3):829-856

New M, Hulme M, Jones P (2000) Representing twentieth-century space-time climate variability. part II: development of 1901-1996 monthly grids of terrestrial surface climate. J Clim 13(13):2217-2238

Parmesan C (2006) Ecological and evolutionary responses to recent climate change. Annu Rev Ecol Evol Syst 37:637-669

Peterson TC, Vose RS (1997) An overview of the global historical climatology network temperature database. Bull Am Meteorol Soc 78(12):2837-2849

Pope VD, Gallani ML, Rowntree PR, Stratton RA (2000) The impact of new physical parametrizations in the Hadley Centre climate model: HadAM3. Clim Dyn 16(2):123-146

Portig WH (1965) Central American rainfall. Geograph Rev 65:68-90

Pounds JA, Fogden MPL, Campbell JH (1999) Biological response to climate change on a tropical mountain. Nature 398(6728):611-615

Pounds JA, Bustamante MR, Coloma LA, Consuegra JA, Fogden MPL, Foster PN, La Marca E, Masters KL, Merino-Viteri A, Puschendorf R, Ron SR, Sanchez-Azofeifa GA, Still CJ, Young BE (2006) Widespread amphibian extinctions from epidemic disease driven by global warming. Nature 439(7073):161-167

Poveda G, Mesa OJ (1999) The low level westerly jet (Choco jet) and two other jets in Colombia: climatology and variability during ENSO phases. Rev Academia Colomb Cienc 23(89):517-528 
Rauscher SA, Giorgi F, Diffenbaugh NS, Seth A (2008) Extension and intensification of the Meso-American mid-summer drought in the twenty-first century. Clim Dyn 31(5):551-571

Rodgers EB, Adler RF, Pierce HF (2001) Contribution of tropical cyclones to the North Atlantic climatological rainfall as observed from satellites. J Appl Meteorol 40:1785-1800

Rudolf B, Schneider U (2005) Calculation of gridded precipitation data for the global land-surface using in-situ gauge observations. Proceedings of the 2nd workshop of the international precipitation working group IPWG, Monterey October 2004, EUMETSAT, ISBN 92-9110-070-6, ISSN 1727-432X, pp 231-247

Rudolf B, Beck C, Grieser J, Schneider U (2005) Global precipitation analysis products. global precipitation climatology centre (GPCC). DWD. Internet publication, pp 1-8

Santer BD, Taylor KE, Wigley TML, Johns TC, Jones PD, Karoly DJ, Mitchell JFB, Oort AH, Penner JE, Ramaswamy V et al (1996) A search for human influences on the thermal structure of the atmosphere. Nature 382(6586):39-46

Santer BD, Wigley TML, Mears C, Wentz FJ, Klein SA, Seidel DJ, Taylor KE, Thorne PW, Wehner MF, Gleckler PJ et al (2005) Amplification of surface temperature trends and variability in the tropical atmosphere. Science 309(5740):1551

Santer BD, Thorne PW, Haimberger L, Taylor KE, Wigley TML, Lanzante JR, Solomon S, Free M, Gleckler PJ, Jones PD et al (2008) Consistency of modelled and observed temperature trends in the tropical troposphere. Int J Climatol 28(13):1703-1722

Seth A, Rauscher SA, Camargo SJ, Qian JH, Pal JS (2007) RegCM3 regional climatologies for South America using reanalysis and ECHAM global model driving fields. Clim Dyn 28(5):461-480

Seth A, Rojas M, Liebmann B, Qian JH (2004) Daily rainfall analysis for South America from a regional climate model and station observations. Geophys Res Lett 31:L07213. doi:10.1029/ 2003GL019220

Small RJO, De Szoeke SP, Xie SP (2007) The Central American midsummer drought: regional aspects and large-scale forcing. J Clim 20(19):4853-4873

Solomon S, Qin D, Manning M, Chen Z, Marquis M, Averyt KB, Tignor M, Miller HL (2008) Climate change 2007: the physical science basis. Cambridge University Press, Cambridgel

Still CJ, Foster PN, Schneider SH (1999) Simulating the effects of climate change on tropical montane cloud forests. Nature 398(6728):608-610

Stuart SN, Chanson JS, Cox NA, Young BE, Rodrigues AS, Fischman DL, Waller RW (2004) Status and trends of amphibian declines and extinctions worldwide. Science 306(5702):1783
Tett SF, Jones GS, Stott PA, Hill DC, Mitchell JF, Allen MR, Ingram WJ, Johns TC, Johnson CE, Jones A, et al (2002) Estimation of natural and anthropogenic contributions to twentieth century temperature change. J Geophys Res 107(10.1029)

Tourigny E, Jones C (2009) An analysis of regional climate model performance over the tropical Americas. part i: simulating seasonal variability of precipitation associated with ENSO forcing. Tellus 61:323-342

Tourigny E, Jones C (2009) An analysis of regional climate model performance over the tropical Americas. part ii: simulating subseasonal variability of precipitation associated with ENSO forcing. Tellus 61A:343-356

Urrutia R, Vuille M (2009) Climate change projections for the tropical Andes using a regional climate model: temperature and precipitation simulations for the end of the 21st century. J Geophys Res Atmosph 114(D2):D02,108

Vuille M, Bradley RS (2000) Mean annual temperature trends and their vertical structure in the tropical Andes. Geophys Res Lett 27(23):3885-3888

Walther GR, Post E, Convey P, Menzel A, Parmesan C, Beebee TJC, Fromentin JM, Hoegh-Guldberg O, Bairlein F (2002) Ecological responses to recent climate change. Nature 416(6879):389-395

Wang C (2007) Variability of the Caribbean low-level jet and its relations to climate. Clim Dyn 29(4):411-422

Wang C, Enfield D (2001) The tropical western hemisphere warm pool. Geophys Res Lett 28(8):1635-1638

Wang C, Fiedler PC (2006) ENSO variability and the eastern tropical Pacific: a review. Prog Oceanograp 69(2-4):239-266

Wang C, Lee S (2007) Atlantic warm pool, Caribbean low-level jet, and their potential impact on Atlantic hurricanes. Geophys Res Lett 34(2):2703

Waylen PR, Caviedes CN, Quesada ME (1996) Interannual variability of monthly precipitation in Costa Rica. J Clim 9:2606-2613

Whitfield SM, Bell KE, Philippi T, Sasa M, nos FBn, Chaves G, Savage JM, Donnelly MA (2007) Amphibian and reptile declines over 35 years at la selva, costa rica. Proc Nat Acad Sci 104(20):8352

Wilks DS (1995) Statistical methods in the atmospheric sciences: An Introduction. Academic Press, San Diego

Wilson SS, Hassell DC, Hein D, Jones RG, Taylor RBE (2004) Installing and using the Hadley Centre regional climate modelling system PRECIS (version 1.0). Met Office Hadley Centre, Exeter

Xie P, Arkin P (1997) Global precipitation: a 17 year monthly analysis based on gauge observations, satellite estimates, and numerical model outputs. Bull Amer Meteor Soc 78:2539-2558 